\title{
Antioxidant and Antidiabetic Activity of Proanthocyanidins from Fagopyrum dibotrys
}

\author{
Xin Li ${ }^{1}{ }^{\oplus}$, Jingling Liu ${ }^{1}$, Qinxiang Chang ${ }^{2}$, Ziyun Zhou ${ }^{1}$, Ruilian Han $^{3}$ and Zongsuo Liang ${ }^{1,3, *}$ \\ 1 College of Life Sciences, Northwest A \& F University, Yangling 712100, China; lixin0715@nwafu.edu.cn (X.L.); \\ jinglingliu-sm@nwsuaf.edu.cn (J.L.); xnzzy@nwsuaf.edu.cn (Z.Z.) \\ 2 Institute of Landscape, Taiyuan University, Taiyuan 030032, China; changqxkys@tyu.edu.cn \\ 3 Zhejiang Provincial Key Laboratory of Plant Secondary Metabolism Regulation, College of Life Science \\ and Medicine, Zhejiang Sci-Tech University, Hangzhou 310018, China; hanrl@nwsuaf.edu.cn \\ * Correspondence: liangzs@ms.iswc.ac.cn; Tel.: +86-13709229238; Fax: +86-571-86843301
}

check for updates

Citation: Li, X.; Liu, J.; Chang, Q.;

Zhou, Z.; Han, R.; Liang, Z.

Antioxidant and Antidiabetic Activity of Proanthocyanidins from Fagopyrum dibotrys. Molecules 2021, 26, 2417.

https://doi.org/10.3390/

molecules26092417

Academic Editor: Anna Petruczynik

Received: 22 March 2021

Accepted: 19 April 2021

Published: 21 April 2021

Publisher's Note: MDPI stays neutral with regard to jurisdictional claims in published maps and institutional affiliations.

Copyright: (c) 2021 by the authors. Licensee MDPI, Basel, Switzerland. This article is an open access article distributed under the terms and conditions of the Creative Commons Attribution (CC BY) license (https:/ / creativecommons.org/licenses/by/ $4.0 /)$.
Abstract: Proanthocyanidins are natural glycosidase inhibitors with excellent antioxidant activity. This study aims to search for a new source of proanthocyanidins for the prevention and treatment of type 2 diabetes with higher content and better activity and get their structure elucidated. First, the total proanthocyanidins contents (TOPCs), antioxidant activity, antidiabetic activity of seven common Polygonaceae plants were analyzed and compared. Then proanthocyanidins from the rhizome of Fagopyrum dibotrys were purified, and the detailed structure was comprehensively analyzed by ultraviolet visible spectroscopy (UV-Vis), Fourier transform infrared spectroscopy (FT-IR), ${ }^{13} \mathrm{C}$ nuclear magnetic resonance spectroscopy $\left({ }^{13} \mathrm{C} N \mathrm{NM}\right)$, reversed-phase high-performance liquid chromatography-electrospray mass spectrometry (RP-HPLC-ESI-MS), and matrix-assisted laser desorption/ionization-time of flight mass spectrometry (MALDI-TOF MS). The rhizome of F. dibotrys showed the highest TOPCs, the strongest antioxidant, and antidiabetic activities; the TOPCs, antioxidant and antidiabetic activities were all very significantly positively correlated. Proanthocyanidins purified from the rhizome of $F$. dibotrys showed better antidiabetic activity than grape seed proanthocyanidins (GsPs). Seventy-two proanthocyanidins from trimer to undecamer with a mean degree of polymerization (mDP) of about $5.02 \pm 0.21$ were identified with catechin and epicatechin as the dominant monomers. Conclusion: Proanthocyanidins are the main antioxidant and antidiabetic active substances of $F$. dibotrys and are expected to be developed into potential antioxidant and hypoglycemic products.

Keywords: Fagopyrum dibotrys; proanthocyanidins; antioxidant; antidiabetes; structural analysis

\section{Introduction}

In recent years, the incidence of type 2 diabetes has been increasing year by year and remains high in the world, which brings great medical and economic burden to society [1]. Glycosidase inhibitors can effectively inhibit the digestion and absorption of sugars in the digestive tract and are highly sought after by diabetic patients because of their high safety and low side effects [2-5]. In addition, antioxidant supplementation can effectively reduce the risk and improve the symptoms of type 2 diabetes and its complications [1,4-6]. Hence, the development of natural glycosidase inhibitors with excellent antioxidant activity has become a hot topic of scientists in recent years [2-5].

Proanthocyanidins are plant polyphenols formed by the condensation of flavane3-ol monomers such as catechin, epicatechin as shown in Figure S1; the diversity of monomer type, composition, substituent group on monomer, linkage-type, and the degree of polymerization together made proanthocyanidins diverse in structure and activity [6]. Proanthocyanidins are widely used in medicine, functional foods, and daily chemical product additives due to their biological activities such as antioxidant, antidiabetes, antiinflammatory, antiallergic, and antimicrobial, etc. [6-8]. Many of the biological activities 
of proanthocyanidins are mainly realized through their excellent antioxidant activity and interaction with proteins [9]. Proanthocyanidins have both excellent antioxidant activity and glycosidase inhibitory activity, which has been proved to be able to effectively relieve oxidative stress while preventing and treating diabetes [2-5]. Therefore, it is of great significance to search for natural plant resources of proanthocyanidins with high content, wide sources, and low cost and to elucidate their structural characteristics for the development of drugs for the prevention and treatment of type 2 diabetes $[1-5,7]$.

The contents and bioactivities of proanthocyanidins in different parts of seven Polygonaceae plants, including Fagopyrum dibotrys [10], Reynoutria japonica [11], and Rheum officinale [12], were compared, and the rhizome of F. dibotrys was selected as the material for further study because it had the highest total proanthocyanidins content (TOPCs), the strongest antioxidant and antidiabetic activity among the seven Polygonaceae plants. F. dibotrys, also known as golden buckwheat, is a perennial erect herb of genus Fagopyrum in Polygonaceae, which mainly grows in the north temperate zone and is widely distributed in China, Kazakhstan, Russia, Ukraine, and other regions [10]. F. dibotrys has rich nutritional value and health care function, and the rhizome of $F$. dibotrys has a long history of being used as an anticancer and anti-inflammatory herb in China $[10,13,14]$. Since substances used in traditional medicine systems have long played a vital role in meeting global healthcare needs, so it is promising to find useful substances from F. dibotrys due to the longtime usage as folk medicine [15].

Modern studies have shown that the rhizome of $F$. dibotrys contains flavonoids, phenols, fagopyritols, triterpenoids, fatty acids, and steroids [10,16-19], which have bioactivities such as antitumor [20-22], anti-oxidation [13,14,23], antidiabetes [24-27] and so on. At present, there are few reports on proanthocyanidins of $F$. dibotrys [10]. It has been reported that proanthocyanidins were isolated from the rhizome of F. dibotrys [10,28]. However, the bioactivity, structural composition, polymerization degree distribution of polymeric proanthocyanidins, and other information of proanthocyanidins of $F$. dibotrys have not been reported yet.

In this study, proanthocyanidins of $F$. dibotrys were used as the research object to analyze the correlation between proanthocyanidins and antioxidant and antidiabetic activities. In addition, ultraviolet visible spectroscopy (UV-Vis) [4,29], Fourier transform infrared spectroscopy (FT-IR) [4,29], ${ }^{13} \mathrm{C}$ nuclear magnetic resonance spectroscopy $\left({ }^{13} \mathrm{C}\right.$ NMR) [30,31], reversed-phase high-performance liquid chromatography-electrospray mass spectrometry (RP-HPLC-ESI-MS) [31-33] and matrix-assisted laser desorption/ionizationtime of flight mass spectrometry (MALDI-TOF MS) [31-33] were comprehensively used to analyze the structure of proanthocyanidins purified from F. dibotrys. It is hoped that this study can provide a reference for the development of the antioxidant and antidiabetes products of $F$. dibotrys.

\section{Results and Discussion}

\subsection{Total Proanthocyanidins Content (TOPCs), Antioxidant and Antidiabetic Activities of Seven Polygonaceae Plants}

The TOPCs, antioxidant and antidiabetic activities of different parts of the seven Polygonaceae plants were analyzed and compared with grape seed as control. The TOPCs of the seven Polygonaceae plants and grape seeds were shown in Table 1. The results showed that proanthocyanidins were detected in all the samples, but The TOPCs in different samples were significantly different. The rhizome of $R$. officinale, the rhizome of $R$. japonica, the rhizome, and shoots of $F$. dibotrys all contained more than $10 \mathrm{mg}$ GsPs /g DW of TOPCs, and the rhizome of $F$. dibotrys was the highest, which was 3.70 and 6.21 times of the rhizome of R. officinale and R. japonica, and 1.09 times of grape seed, respectively. In addition, the TOPCs of the rhizome of $F$. dibotrys were about 6.49 times that of the shoots of $F$. dibotrys. The results showed that the content of proanthocyanidins not only varied in different plants of the same family but also varied in different parts of the same plant [13,34]. 
Table 1. The TOPCs of seven plant materials of the Polygonaceae family and grape seed.

\begin{tabular}{ccc}
\hline Category & Plant Sample & TOPCs $\mathbf{( m g ~ G s P s / g ~ D W ) ~}$ \\
\hline Control & Grape seed & $75.24 \pm 0.98^{\mathrm{b}}$ \\
A & Rhizome of . dibotrys & $82.14 \pm 0.51^{\mathrm{a}}$ \\
B & Shoots of . dibotrys & $12.66 \pm 0.44^{\mathrm{e}}$ \\
C & $4.18 \pm 0.33^{\mathrm{g}}$ \\
D & Rhizome of F. multiflora & $0.94 \pm 0.42^{\mathrm{ij}}$ \\
E & Shoots of . multiflora & $0.82 \pm 0.18^{\mathrm{j}}$ \\
F & Whole plant of P. aviculare & $0.35 \pm 0.09^{\mathrm{k}}$ \\
G & Whole plant of P. orientale & $13.22 \pm 0.44^{\mathrm{d}}$ \\
H & Rhizome of $R$. japonica & $0.50 \pm 0.27^{\mathrm{k}}$ \\
I & Shoots of R. japonica & $22.19 \pm 0.35^{\mathrm{c}}$ \\
J & Rhizome of R. officinale & $1.34 \pm 0.50^{\mathrm{i}}$ \\
K & Shoots of $R$. officinale & $8.28 \pm 0.14^{\mathrm{f}}$ \\
L & Rhizome of R. acetosa & $3.82 \pm 0.10^{\mathrm{h}}$ \\
\hline
\end{tabular}

Different lowercase letters in each column indicate significant differences at the $p<0.05$ level.

The antioxidant activities of the seven Polygonaceae plants and grape seeds are shown in Table 2. The DPPH free radical scavenging rate and CUPRAC value of the rhizome of F. dibotrys were significantly higher than those of grape seed and other Polygonaceae plants. The ABTS free radical scavenging rate and FRAP value of the rhizome of $F$. dibotrys were about 1.01 and 0.89 times those of grape seed and significantly higher than those of other Polygonaceae plants. The order of antioxidant activity of different samples was relatively consistent with their TOPCs.

Table 2. The antioxidant activity of DPPH, ABTS, FRAP, and CUPRAC of seven plant materials of the Polygonaceae family and grape seed.

\begin{tabular}{ccccc}
\hline Category & $\begin{array}{c}\text { DPPH } \\
\text { Scavenging (\%) }\end{array}$ & $\begin{array}{c}\text { ABTS } \\
\text { Scavenging (\%) }\end{array}$ & $\begin{array}{c}\text { FRAP/mg Vc/g } \\
\text { Equivalent }\end{array}$ & $\begin{array}{c}\text { CUPRAC/mg } \\
\text { Trolox/g Equivalent }\end{array}$ \\
\hline Control & $67.68 \pm 0.25^{\mathrm{b}}$ & $92.57 \pm 0.74^{\mathrm{a}}$ & $115.95 \pm 0.85^{\mathrm{a}}$ & $208.89 \pm 2.24^{\mathrm{b}}$ \\
A & $72.11 \pm 0.42^{\mathrm{a}}$ & $93.20 \pm 0.29^{\mathrm{a}}$ & $103.12 \pm 1.50^{\mathrm{b}}$ & $215.23 \pm 0.59^{\mathrm{a}}$ \\
$\mathrm{B}$ & $22.48 \pm 0.19^{\mathrm{g}}$ & $28.75 \pm 1.36^{\mathrm{h}}$ & $25.46 \pm 0.38^{\mathrm{g}}$ & $48.45 \pm 1.32^{\mathrm{g}}$ \\
$\mathrm{C}$ & $32.28 \pm 0.33^{\mathrm{f}}$ & $39.25 \pm 0.28^{\mathrm{f}}$ & $68.84 \pm 0.86^{\mathrm{e}}$ & $156.20 \pm 3.25^{\mathrm{c}}$ \\
$\mathrm{D}$ & $9.12 \pm 0.48^{\mathrm{k}}$ & $22.48 \pm 0.30^{\mathrm{i}}$ & $6.58 \pm 0.32^{\mathrm{k}}$ & $14.23 \pm 0.85^{\mathrm{m}}$ \\
$\mathrm{E}$ & $6.75 \pm 0.50^{\mathrm{m}}$ & $11.34 \pm 0.25^{\mathrm{k}}$ & $11.13 \pm 0.45^{\mathrm{i}}$ & $26.04 \pm 1.20^{\mathrm{i}}$ \\
$\mathrm{F}$ & $8.49 \pm 0.24^{\mathrm{l}}$ & $20.28 \pm 0.19^{\mathrm{j}}$ & $16.92 \pm 0.32^{\mathrm{h}}$ & $37.67 \pm 0.47^{\mathrm{h}}$ \\
$\mathrm{G}$ & $44.62 \pm 0.36^{\mathrm{d}}$ & $58.69 \pm 0.40^{\mathrm{c}}$ & $71.42 \pm 0.29^{\mathrm{d}}$ & $128.29 \pm 2.19^{\mathrm{e}}$ \\
$\mathrm{H}$ & $18.23 \pm 0.19^{\mathrm{h}}$ & $41.08 \pm 0.28^{\mathrm{e}}$ & $9.79 \pm 0.08^{\mathrm{j}}$ & $22.14 \pm 0.56^{1}$ \\
$\mathrm{I}$ & $36.50 \pm 0.42^{\mathrm{e}}$ & $58.17 \pm 0.13^{\mathrm{d}}$ & $76.60 \pm 0.94^{\mathrm{c}}$ & $131.25 \pm 0.47^{\mathrm{d}}$ \\
$\mathrm{J}$ & $14.25 \pm 0.28^{\mathrm{i}}$ & $31.20 \pm 0.96^{\mathrm{g}}$ & $11.49 \pm 0.40^{\mathrm{i}}$ & $24.30 \pm 0.32^{\mathrm{j}}$ \\
K & $45.40 \pm 0.63^{\mathrm{c}}$ & $67.25 \pm 1.27^{\mathrm{b}}$ & $53.49 \pm 0.34^{\mathrm{f}}$ & $118.21 \pm 0.18^{\mathrm{f}}$ \\
$\mathrm{L}$ & $12.14 \pm 0.19^{\mathrm{j}}$ & $20.38 \pm 0.50^{\mathrm{j}}$ & $10.16 \pm 0.69^{\mathrm{j}}$ & $23.28 \pm 0.79^{\mathrm{k}}$ \\
\hline
\end{tabular}

Different lowercase letters in each column indicate significant differences at the $p<0.05$ level.

The antidiabetic activities of the seven Polygonaceae plants and grape seeds are shown in Table 3. The inhibitory activities of the rhizome of $F$. dibotrys against S. cerevisiae $\alpha$-glucosidase, porcine pancreatic $\alpha$-amylase, and human salivary $\alpha$-amylase were significantly stronger than those of other Polygonaceae plants. Moreover, the inhibitory activities of the rhizome of $F$. dibotrys against $S$. cerevisiae $\alpha$-glucosidase, porcine pancreatic $\alpha$-amylase, and human salivary $\alpha$-amylase were $0.86,0.97$, and 1.15 times of those of grape seed, respectively, indicating that the rhizome of $F$. dibotrys and grape seed had similar antidiabetes activity. Similar to the results of antioxidant analysis, the order of antidiabetic activities of different samples was also in high consistency with their respective TOPCs. 
Table 3. The inhibitory activity of seven plant materials of the Polygonaceae family and grape seed against $S$. cerevisiae $\alpha$-glucosidase, porcine pancreatic $\alpha$-amylase, and human salivary $\alpha$-amylase.

\begin{tabular}{cccc}
\hline Category & $\begin{array}{c}\text { S.cerevisiae } \alpha \text {-Glucosidase } \\
\text { Inhibition (\%) }\end{array}$ & $\begin{array}{c}\text { Porcine Pancreatic } \\
\boldsymbol{\alpha} \text {-Amylase } \\
\text { Inhibition (\%) }\end{array}$ & $\begin{array}{c}\text { Human Salivary } \\
\boldsymbol{\alpha} \text {-Amylase } \\
\text { Inhibition (\%) }\end{array}$ \\
\hline Control & $96.29 \pm 1.32^{\mathrm{a}}$ & $98.75 \pm 0.49^{\mathrm{a}}$ & $74.28 \pm 2.21^{\mathrm{b}}$ \\
A & $83.17 \pm 0.88^{\mathrm{b}}$ & $96.27 \pm 1.28^{\mathrm{b}}$ & $85.76 \pm 0.48^{\mathrm{a}}$ \\
$\mathrm{B}$ & $14.59 \pm 0.24^{\mathrm{g}}$ & $10.23 \pm 0.36^{\mathrm{h}}$ & $5.26 \pm 0.34^{\mathrm{gh}}$ \\
C & $29.54 \pm 1.44^{\mathrm{e}}$ & $32.18 \pm 0.27^{\mathrm{d}}$ & $17.64 \pm 1.42^{\mathrm{d}}$ \\
D & $8.79 \pm 0.55^{\mathrm{i}}$ & $10.20 \pm 1.38^{\mathrm{h}}$ & $4.78 \pm 0.59^{\mathrm{h}}$ \\
E & $2.46 \pm 1.82^{\mathrm{k}}$ & $5.45 \pm 0.59^{\mathrm{j}}$ & $1.65 \pm 0.16^{\mathrm{j}}$ \\
F & $4.18 \pm 1.33^{\mathrm{k}}$ & $7.60 \pm 0.72^{\mathrm{i}}$ & $3.44 \pm 0.84^{\mathrm{i}}$ \\
G & $37.94 \pm 3.16^{\mathrm{d}}$ & $30.28 \pm 0.46^{\mathrm{e}}$ & $16.29 \pm 0.23^{\mathrm{d}}$ \\
$\mathrm{H}$ & $6.50 \pm 1.22^{\mathrm{j}}$ & $8.51 \pm 2.28^{\mathrm{hi}}$ & $3.51 \pm 0.96^{\mathrm{i}}$ \\
I & $60.29 \pm 1.44^{\mathrm{c}}$ & $45.46 \pm 1.59^{\mathrm{c}}$ & $40.24 \pm 2.10^{\mathrm{c}}$ \\
J & $8.68 \pm 0.13^{\mathrm{i}}$ & $12.49 \pm 0.33^{\mathrm{g}}$ & $7.57 \pm 0.96^{\mathrm{f}}$ \\
K & $24.29 \pm 2.44^{\mathrm{f}}$ & $18.35 \pm 2.12^{\mathrm{f}}$ & $11.39 \pm 1.05^{\mathrm{e}}$ \\
L & $12.52 \pm 1.67^{\mathrm{h}}$ & $10.49 \pm 0.56^{\mathrm{h}}$ & $5.62 \pm 0.32^{\mathrm{g}}$ \\
\hline
\end{tabular}

Different lowercase letters in each column indicate significant differences at the $p<0.05$ level.

As shown in the above tables, the rhizome of $F$. dibotrys showed the highest TOPCs, the strongest antioxidant activity and the strongest antidiabetic activity among the seven Polygonaceae plants. Moreover, the TOPCs, antioxidant activity and antidiabetes activity of the rhizome of $F$. dibotrys were similar to those of grape seed. Vast studies showed that the main components of the antioxidant and antidiabetic activities of grape seed were proanthocyanidins $[1-10,34,35]$. In addition, this study found that the order of TOPCs of the samples was highly consistent with the order of all the antioxidant and antidiabetic indexes. To better explore the correlation between TOPCs and antioxidant and antidiabetic activities in these Polygonaceae plants, Pearson correlation coefficient between TOPCs and antioxidant and antidiabetic activity in each sample was analyzed and the results were shown in Table 4 . The results showed that TOPCs were significantly positively correlated with antioxidant and antidiabetic activities, and all the antioxidant activities and antidiabetic activities were significantly positively correlated with each other. All the correlation coefficients reached the $p<0.01$ level, indicating that proanthocyanidins may be important antioxidant and antidiabetic compounds in these Polygonaceae plants.

Table 4. The Pearson correlation coefficient between TOPCs, and antioxidant and antidiabetic activity.

\begin{tabular}{|c|c|c|c|c|c|c|c|}
\hline Pearson Correlation Coefficient & TOPCs & DPPH & ABTS & FRAP & CUPRAC & $\alpha$-glu & PPA \\
\hline DPPH & $0.8765^{* *}$ & & & & & & \\
\hline ABTS & $0.8565^{* *}$ & $0.9785^{* *}$ & & & & & \\
\hline FRAP & $0.8331^{* *}$ & $0.9487^{* *}$ & $0.9092^{* *}$ & & & & \\
\hline CUPRAC & $0.8190^{* *}$ & $0.9495^{* *}$ & $0.8995^{* *}$ & $0.9880^{* *}$ & & & \\
\hline$\alpha$-glu & $0.9295^{* *}$ & $0.9217^{* *}$ & $0.9091^{* *}$ & $0.9512^{* *}$ & $0.9177^{* *}$ & & \\
\hline PPA & $0.9694^{* *}$ & $0.9080^{* *}$ & $0.8905^{* *}$ & $0.9163^{* *}$ & $0.9020^{* *}$ & $0.9774^{* *}$ & \\
\hline HSA & $0.9753^{* *}$ & $0.8863^{* *}$ & $0.8763^{* *}$ & $0.8829^{* *}$ & $0.8706^{* *}$ & $0.9641^{* *}$ & $0.9898^{* *}$ \\
\hline
\end{tabular}

** indicates significant correlations at the $p<0.01$ level.

\subsection{Purification and Bioactivity of Proanthocyanidins from the Rhizome of F. dibotrys}

The above studies showed that the rhizome of F. dibotrys contained the most abundant proanthocyanidins and exhibited the strongest antioxidant and antidiabetic activities among the selected Polygonaceae plant samples. To better reveal the relationship between the TOPCs and its biological activity in the rhizome of $F$. dibotrys, a 50\% methanol eluent and a $70 \%$ acetone eluent were successively obtained from the crude extract of the rhizome of $F$. dibotrys by Sephadex LH-20 and the TOPCs of the three extracts were determined 
and were shown in Table 5. The TOPCs of the $50 \%$ methanol eluent, crude extract and the $70 \%$ acetone eluent of the crude extract of the rhizome of F. dibotrys increased in turn, and the TOPCs of the $70 \%$ acetone eluent was 4.99 times and 79.48 times of crude extract and the $50 \%$ methanol eluent respectively, indicating that Sephadex LH-20 could effectively achieve the enrichment of proanthocyanidins in crude extract of the rhizome of F. dibotrys.

Table 5. Comparison of TOPCs of the 50\% methanol eluent, crude extract and the $70 \%$ acetone eluent of rhizome of F. dibotrys.

\begin{tabular}{cc}
\hline Category & TOPCs (mg GsPs/g DW) \\
\hline $50 \%$ methanol eluent & $15.39 \pm 0.25^{\mathrm{c}}$ \\
Crude extract & $245.24 \pm 4.71^{\mathrm{b}}$ \\
$70 \%$ acetone eluent & $1223.15 \pm 20.64^{\mathrm{a}}$ \\
\hline
\end{tabular}

Different lowercase letters in each column indicate significant differences at the $p<0.05$ level.

The antioxidant activities of the three extracts were shown in Table 6. The DPPH radical scavenging activity, ABTS radical scavenging activity, FRAP antioxidant activity and CUPRAC antioxidant activity of the 50\% methanol eluent, crude extract and the $70 \%$ acetone eluent of the rhizome of $F$. dibotrys were all increased successively, which were consistent with the order of their TOPCs. The DPPH free radical scavenging activity, ABTS free radical scavenging activity and CUPRAC antioxidant activity of the $70 \%$ acetone eluent were significantly higher than those of $\mathrm{Vc}$ and Trolox, and the antioxidant activities of the $70 \%$ acetone eluent were 2.92 3.36 times those of crude extract, 5.27 6.28 times those of the $50 \%$ methanol eluent, and 0.93 1.05 times those of GsPs, indicating that the antioxidant activities of proanthocyanidins obtained from the crude extract of the rhizome of $F$. dibotrys had been enriched by Sephadex LH-20 and were close to those of GsPs.

Table 6. The antioxidant activities of DPPH, ABTS, FRAP and CUPRAC of the 50\% methanol eluent, crude extract and the $70 \%$ acetone eluent of rhizome of F. dibotrys, GsPs, Vc and Trolox.

\begin{tabular}{ccccc}
\hline Category & EC $_{\mathbf{5 0}} / \mathrm{DPPH}(\boldsymbol{\mu g} / \mathbf{m L})$ & EC $_{\mathbf{5 0}} / \mathrm{ABTS}(\mu \mathrm{g} / \mathrm{mL})$ & $\begin{array}{c}\text { FRAP/mg } \\
\text { Vc/g Equivalent }\end{array}$ & $\begin{array}{c}\text { CUPRAC/mg } \\
\text { Trolox/g Equivalent }\end{array}$ \\
\hline $50 \%$ methanol eluent & $514.58 \pm 4.42^{\mathrm{a}}$ & $288.78 \pm 2.36^{\mathrm{a}}$ & $113.20 \pm 1.47^{\mathrm{e}}$ & $323.28 \pm 3.80^{\mathrm{d}}$ \\
Crude extract & $239.46 \pm 2.18^{\mathrm{b}}$ & $184.3 \pm 1.96^{\mathrm{b}}$ & $278.22 \pm 2.12^{\mathrm{d}}$ & $581.74 \pm 5.25^{\mathrm{c}}$ \\
$70 \%$ acetone eluent & $82.00 \pm 0.63^{\mathrm{e}}$ & $54.78 \pm 0.45^{\mathrm{d}}$ & $674.52^{\mathrm{a}} \pm 4.64^{\mathrm{c}}$ & $1999.71 \pm 14.31^{\mathrm{a}}$ \\
GsPs & $86.25 \pm 0.77^{\mathrm{d}}$ & $54.47 \pm 0.35^{\mathrm{d}}$ & $728.55 \pm 4.62^{\mathrm{b}}$ & $1996.59 \pm 18.45^{\mathrm{a}}$ \\
Vc & $128.33 \pm 0.75^{\mathrm{c}}$ & $82.53 \pm 0.96^{\mathrm{c}}$ & $1000.00 \pm 11.45^{\mathrm{a}}$ & - \\
Trolox & - & - & - & $1000.00 \pm 16.86^{\mathrm{b}}$ \\
\hline
\end{tabular}

Different lowercase letters in each column indicate significant differences at the $p<0.05$ level.

The antidiabetic activities of the $50 \%$ methanol eluent, crude extract and the $70 \%$ acetone eluent of the rhizome of $F$. dibotrys were shown in Table 7 . The inhibitory activities of the $50 \%$ methanol eluent, crude extract and the $70 \%$ acetone eluent of the rhizome of F. dibotrys against $S$. cerevisiae $\alpha$-glucosidase, porcine pancreatic $\alpha$-amylase and human salivary $\alpha$-amylase were all increased successively, which were consistent with the order of their TOPCs and antioxidant activities. The inhibitory activities of the $70 \%$ acetone eluent against the three glycosidases were 5.11 8.73 times of crude extract and 55.87 112.78 times of the $50 \%$ methanol eluent, and 1.09 1.18 times of GsPs. Moreover, the inhibitory activity of the $70 \%$ acetone eluent against S. cerevisiae $\alpha$-glucosidase, was about 190.86 times that of acarbose. All these indicated that the proanthocyanidins obtained from the crude extract of the rhizome of $F$. dibotrys and enriched by Sephadex LH-20 had strong antidiabetic activities, and the activities were significantly higher than those of GsPs. 
Table 7. The inhibitory activities of the $50 \%$ methanol eluent, crude extract and the $70 \%$ acetone eluent of rhizome of $F$. dibotrys, GsPs and acarbose against $S$. cerevisiae $\alpha$-glucosidase, porcine pancreatic $\alpha$-amylase and human salivary $\alpha$-amylase.

\begin{tabular}{cccc}
\hline Category & $\begin{array}{c}\text { IC }_{50} / \text { S. cerevisiae } \\
\alpha \text {-Glucosidase } \\
(\mu \mathrm{g} / \mathrm{mL})\end{array}$ & $\begin{array}{c}\mathrm{IC}_{50} / \text { Porcine } \\
\text { Pancreatic } \\
\boldsymbol{\alpha} \text {-Amylase } \\
(\mu \mathrm{g} / \mathrm{mL})\end{array}$ & $\begin{array}{c}\mathrm{IC}_{50} / \mathrm{Human} \\
\text { Salivary } \\
\boldsymbol{\alpha} \text {-Amylase } \\
(\mu \mathrm{g} / \mathrm{mL})\end{array}$ \\
\hline $50 \%$ methanol eluent & $144.36 \pm 7.53^{\mathrm{b}}$ & $267.29 \pm 6.28^{\mathrm{a}}$ & $428.50 \pm 5.18^{\mathrm{a}}$ \\
Crude extract & $6.54 \pm 1.36^{\mathrm{c}}$ & $36.51 \pm 0.87^{\mathrm{b}}$ & $58.39 \pm 1.49^{\mathrm{b}}$ \\
$70 \%$ acetone eluent & $1.28 \pm 0.04^{\mathrm{e}}$ & $4.18 \pm 0.12^{\mathrm{d}}$ & $7.67 \pm 0.18^{\mathrm{d}}$ \\
GsPs & $1.51 \pm 0.02^{\mathrm{d}}$ & $4.55 \pm 0.08^{\mathrm{c}}$ & $9.01 \pm 0.24^{\mathrm{c}}$ \\
Acarbose & $244.30 \pm 5.25^{\mathrm{a}}$ & $0.45 \pm 0.03^{\mathrm{e}}$ & $1.26 \pm 0.12^{\mathrm{e}}$ \\
\hline
\end{tabular}

Different lowercase letters in each column indicate significant differences at the $p<0.05$ level.

The comparison of TOPCs, antioxidant and antidiabetic activities of crude extract, the $50 \%$ methanol eluent and the $70 \%$ acetone eluent of the rhizome of $F$. dibotrys showed that all the antioxidant and antidiabetic indexes of the three extracts were enhanced with the increase in TOPCs, and the antioxidant activities of the 70\% acetone eluent with the highest TOPCs were similar to those of GsPs, while the antidiabetic activities were significantly stronger than those of GsPs. All these further confirmed that proanthocyanidins were the main antioxidant and antidiabetic active substances in the rhizome of $F$. dibotrys.

\subsection{Structure Analysis of Proanthocyanidins in the Rhizome of F. dibotrys}

There have been no reports about the detailed structure of proanthocyanidins in the rhizome of $F$. dibotrys so far. To better study and develop the proanthocyanidins in F. dibotrys, it was important and necessary to analyze the structure of proanthocyanidins. Therefore, UV-Vis, FT-IR, ${ }^{13}$ C NMR, RP-HPLC-ESI-MS, and MALDI-TOF MS were used to analyze the structure of proanthocyanidins in the $70 \%$ acetone eluent of the rhizome of F. dibotrys in this study.

\subsubsection{UV-vis Analysis}

As a class of compounds containing conjugated structures, the solution of proanthocyanidins has characteristic absorption peaks in the ultraviolet region. The ultraviolet spectrum of a typical proanthocyanidins solution should have two absorption peaks located near $230 \mathrm{~nm}$ and $280 \mathrm{~nm}$, respectively. In general, the absorption peak near $280 \mathrm{~nm}$ is symmetric, and there should be no absorption peak in the wavelength range greater than $280 \mathrm{~nm}$. Under the same mass concentration, the intensity of the absorption peak near $230 \mathrm{~nm}$ should be significantly greater than that near $280 \mathrm{~nm}[4,28]$. The n-butanolhydrochloric acid colorimetric method is the most classical and most widely recognized method for the analysis of proanthocyanidins. Proanthocyanidins can be hydrolyzed to produce anthocyanins in a hot acidic environment, while anthocyanins have an absorption peak near $550 \mathrm{~nm}$ in an acidic environment, so the purpose of analyzing proanthocyanidins can be achieved by analyzing the generated anthocyanins [34,35].

In this study, GsPs were used as the control to compare the UV-Vis spectrum of the $70 \%$ acetone eluent of the rhizome of $F$. dibotrys under the same experimental conditions and with the same concentrations, and the results are shown in Figure 1. According to their respective spectral curves, both the $70 \%$ acetone eluent of the rhizome of $F$. dibotrys and GsPs exhibited the same characteristic absorption peaks, and no impurity peaks that should not appear were detected. The results showed that the $70 \%$ acetone eluent of the rhizome of $F$. dibotrys contained proanthocyanidins with relatively high purity, which was consistent with the previous results that the TOPCs of the 70\% acetone eluent of the rhizome of F. dibotrys was as high as $1223.15 \pm 20.64 \mathrm{mg}$ GsPs /g DW [4,29,35,36]. 

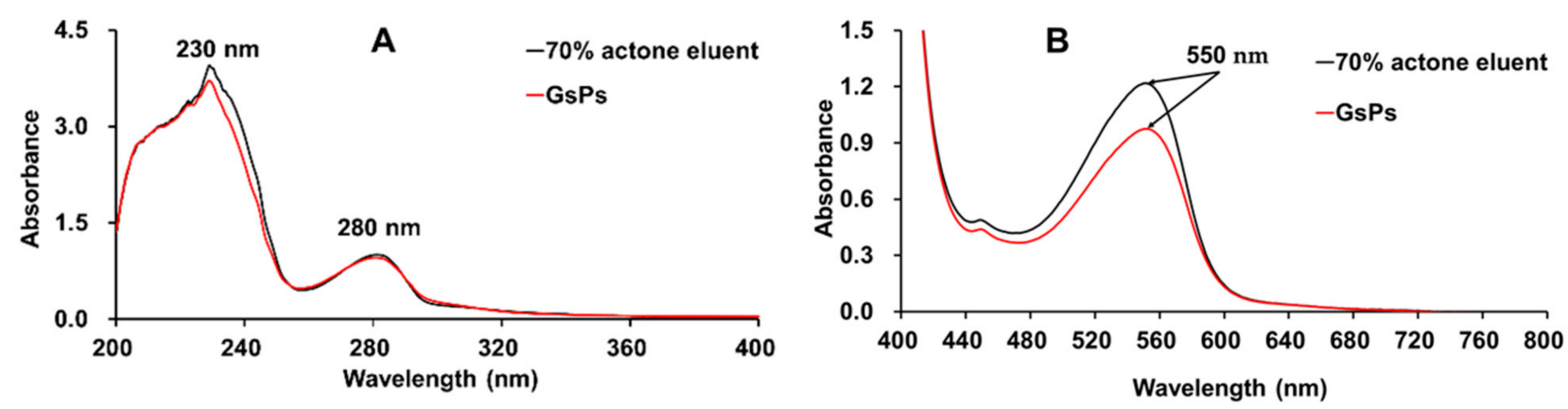

Figure 1. (A) The ultraviolet spectrum of the $70 \%$ acetone eluent of the rhizome of F. dibotrys and GsPs in methanol solution, (B) the visible spectrum of the 70\% acetone eluent of the rhizome of F. dibotrys and GsPs after color development by n-butanol-hydrochloric acid colorimetric method.

\subsubsection{FT-IR Analysis}

The FT-IR analysis can provide some functional group information of proanthocyanidins. The absorption peaks of hydroxyl and benzene ring skeleton on flavan3-ol monomers are the main characteristic absorption peaks of proanthocyanidins in the FT-IR spectrum $[4,29]$. In this study, the FT-IR spectrum of the $70 \%$ acetone eluent of the rhizome of $F$. dibotrys and GsPs were obtained, as shown in Figure 2.

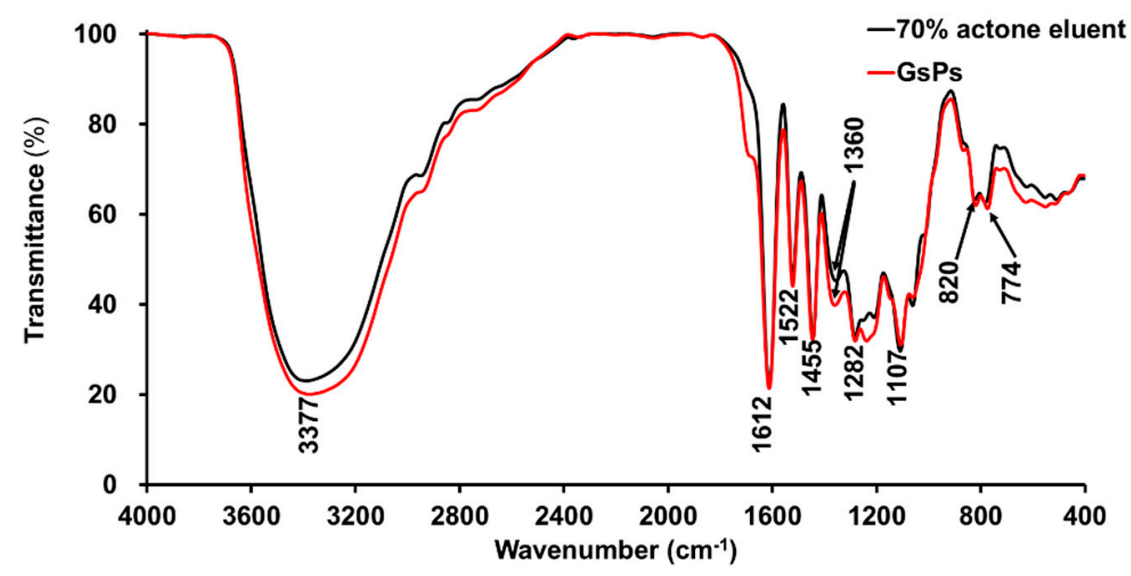

Figure 2. The FT-IR spectrum of the $70 \%$ acetone eluent of the rhizome of F. dibotrys and GsPs.

In the spectrum, the absorption peak near $3377 \mathrm{~cm}^{-1}$ was the stretching vibration absorption peak of the hydroxyl group in phenolic molecules, and the less obvious absorption peak near $2900 \mathrm{~cm}^{-1}$ was the antisymmetric stretching vibration absorption peak of $=\mathrm{C}-\mathrm{H}$ in the benzene ring. The less obvious absorption peak near $2850 \mathrm{~cm}^{-1}$ was the symmetric stretching vibration absorption peak of $=\mathrm{C}-\mathrm{H}$ on the benzene ring. There was no significant absorption peak of the $70 \%$ acetone eluent of the rhizome of $F$. dibotrys near $1700 \mathrm{~cm}^{-1}$ in the spectrum, while GsPs could detect a relatively weak absorption peak, which was the carbonyl group signal on the galloyl group, indicating that the degree of gallic acylation of the $70 \%$ acetone eluent was relatively low compared with GsPs, so that it could not be detected by FT-IR. The absorption peaks near 1612,1522 and $1455 \mathrm{~cm}^{-1}$ were the skeleton stretching vibration absorption peaks of the benzene ring. The absorption peak near 1360 $\mathrm{cm}^{-1}$ came from the bending vibration absorption peak of phenolic hydroxyl group. The absorption peaks near 1282 and $1200 \mathrm{~cm}^{-1}$ were the symmetric and antisymmetric stretching vibration absorption peaks of $\mathrm{C}-\mathrm{O}-\mathrm{C}$ ether bond on the heterocycle. The absorption peak near $1107 \mathrm{~cm}^{-1}$ was the in-plane bending vibration absorption peak of $=\mathrm{C}-\mathrm{H}$ on the benzene ring. The absorption peaks near 820 and $774 \mathrm{~cm}^{-1}$ were the out-of-plane bending vibration absorption peaks of $=\mathrm{C}-\mathrm{H}$ on the benzene ring. In the fingerprint region 
of $1300-400 \mathrm{~cm}^{-1}$, the $70 \%$ acetone eluent and GsPs had similar absorption peaks but with some differences, which indicates that the $70 \%$ acetone eluent and GsPs should have a similar structure but with some differences and the detailed structure of the $70 \%$ acetone eluent of the rhizome of F. dibotrys needs to be further analyzed [4,29].

\subsection{3. ${ }^{13} \mathrm{C}$ NMR Analysis}

The ${ }^{13} \mathrm{C}$ NMR of proanthocyanidins can provide abundant structural information of proanthocyanidins, including the composition, proportion, the three-dimensional configuration, and the linkage type of monomers, as well as the degree of polymerization of proanthocyanidins, etc. [9,30-33,37-39].

The ${ }^{13} \mathrm{C}$ NMR spectrum analysis results of the $70 \%$ acetone eluent of the rhizome of F. dibotrys and GsPs are shown in Figure 3. The wide peaks between 157 and 150 ppm attributed to the signals of C5, C7, and C8a on the A ring, and the peaks between 145 and 115 ppm belonged to the signals of $C 3^{\prime}, C 4^{\prime}, C 1^{\prime}, C 6^{\prime}$, and the $C 2^{\prime}$ and $\mathrm{C}^{\prime}$ signals of procyanidins on the $\mathrm{B}$ ring. The peaks between 110 and $90 \mathrm{ppm}$ belonged to the signals of C8, C6, and C4a in the extension and terminal units. The peaks between 90 and 60 ppm belonged to the signals of C2 and C3 in the extension and terminal units. While the peaks near 36 and 28 ppm were the C4 signal of the extension units and terminal units. The peaks near 39.5 ppm were the carbon signals of the solvent DMSO- $d_{6}[33,38,39]$.

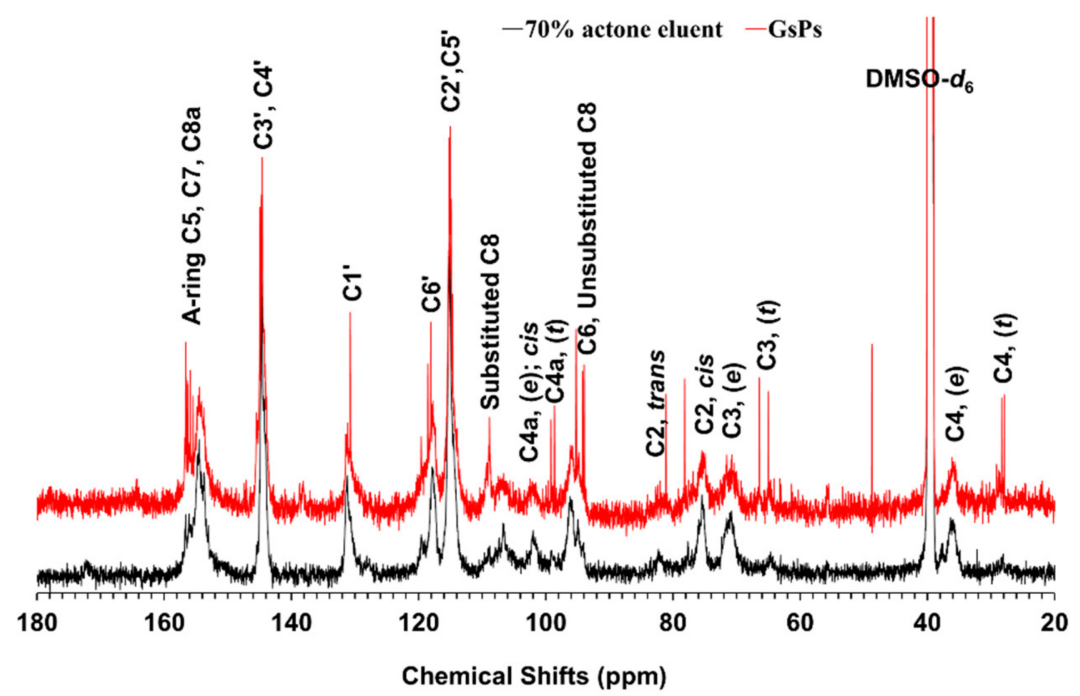

Figure 3. The ${ }^{13} \mathrm{C}$ NMR spectrum the $70 \%$ acetone eluent of the rhizome of $F$. dibotrys and GsPs.

By comprehensively analysis of the ${ }^{13} \mathrm{C}$ NMR spectrum of the $70 \%$ acetone eluent of the rhizome of F. dibotrys and GsPs, it can be concluded that the proanthocyanidins in the $70 \%$ acetone eluent of the rhizome of F. dibotrys and GsPs were similar in structure and were mainly composed of (epi)catechin monomers, no obvious (epi)gallocatechin monomers, gallic acylated monomers, and A-type linkage were detected [9,38,39]. The 2'3-cis configuration was dominant, and the ratio of 2'3-cis to 2'3-trans configuration was about 4:1 [9]. According to the ratio of the peak areas of C3 and C4 in the extension and terminal units, the mean degree of polymerization (mDP) of proanthocyanidins in the $70 \%$ acetone eluent was estimated to be about 5 [9].

\subsubsection{RP-HPLC-ESI-MS Analysis of Thiolytic Degradation Products}

Under acidic conditions, the nucleophile benzyl mercaptan can degrade the proanthocyanidins, the terminal units are released in the form of flavane-3-ols, while the extension units can form the corresponding benzyl thioether with benzyl mercaptan. During the degradation of proanthocyanidins by benzyl mercaptan, the three-dimensional configurations of $\mathrm{C} 2$ and $\mathrm{C} 3$ on the $\mathrm{C}$-ring of the monomers were not affected, and the C-C and 
$\mathrm{C}-\mathrm{O}-\mathrm{C}$ double bonds in the A-type linkage were not affected and retained. Therefore, the analysis of thiolytic degradation products can deduce the structure of proanthocyanidins backward so as to obtain the specific composition of terminal units and extension units as well as the polymerization degree information, which is considered to be an effective method to analyze the structure of proanthocyanidins [30-34].

In this study, RP-HPLC-ESI-MS was used to analyze the thiolytic degradation products of the $70 \%$ acetone eluent of the rhizome of $F$. dibotrys. The HPLC spectrum of thiolytic degradation products are shown in Figure 4. The molecular ions $[\mathrm{M}-\mathrm{H}]^{-}$of peaks $1-3$ were $m / z 289,289$, and 441 , respectively; by comparing the retention time and mass spectrum data of standard references, it was determined that peaks 1-3 were catechin, epicatechin, and epicatechin gallate, respectively, which were the terminal units [33,34]. While the molecular ions $[\mathrm{M}-\mathrm{H}]^{-}$of peaks $4-11$ were $m / z 427,427,411,411,563$, 697,395 , and 123, respectively, by comparing the mass spectrum data and combining with the reference literature [34], it was determined that peaks 4-11 were gallocatechin benzyl thioether, epigallocatechin benzyl thioether, catechin benzyl thioether, epicatechin benzyl thioether, (epi)catechin gallate benzyl thioether, the benzyl thioether of an A-type dimer composed of two (epi)catechin monomers, (epi)afzelechin benzyl thioether and excessive benzyl mercaptan, respectively. So, the extension units were epigallocatechin, gallocatechin, catechin, epicatechin, (epi)catechin gallate, (epi)afzelechin, and A-type dimer, respectively [33].

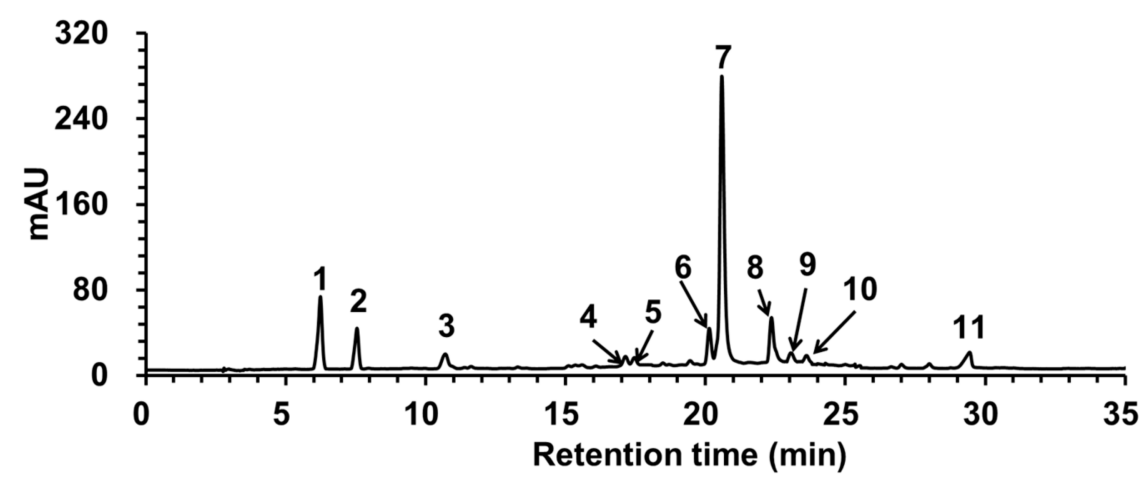

Figure 4. The RP-HPLC spectrum of thiolytic degradation products of the $70 \%$ acetone eluent of the rhizome of F. dibotrys.

The structural composition of proanthocyanidins in the $70 \%$ acetone eluent of the rhizome of F. dibotrys is shown in Table 8. Catechin and epicatechin together constituted about $90 \%$ of the monomers, and the A-type linkages existed only in the extension unit, which accounted for $0.78 \%$ of all the monomers was also composed of two (epi)catechin monomers, but the proportion of catechin and epicatechin in the extension units and terminal units were significantly different. The 2'3-cis configuration was dominant, and the proportion of 2'3-cis configuration was about $79.13 \% \pm 0.85 \%$, which was consistent with the ${ }^{13} \mathrm{C}$ NMR result that the ratio of $2^{\prime} 3$-cis to $2^{\prime} 3$-trans configuration was about 4:1. The calculated $\mathrm{mDP}$ was about $5.02 \pm 0.21$, which was also consistent with the ${ }^{13} \mathrm{C}$ NMR analysis results. Owing to the higher sensitivity of RP-HPLC-ESI-MS, (epi)catechin gallate was detected from both extension and terminal units, indicating a certain degree of gallic acylation of monomers [33]. Meanwhile, gallocatechin and epigallocatechin were detected from the extension units, and the presence of (epi)afzelechin was also detected from the extension units. In conclusion, the above structural information should provide a reference for the subsequent MALDI-TOF MS analysis. 
Table 8. Analysis results of benzyl mercaptan degradation products of the $70 \%$ acetone eluent of the rhizome of $F$. dibotrys by RP-HPLC.

\begin{tabular}{|c|c|c|c|}
\hline Category & Peak No. & Sort & Value \\
\hline \multirow{3}{*}{ Terminal Units (\%) } & 1 & $\mathrm{C}$ & $11.69 \pm 0.46$ \\
\hline & 2 & $\mathrm{EC}$ & $6.83 \pm 1.03$ \\
\hline & 3 & ECG & $1.41 \pm 0.53$ \\
\hline \multirow{7}{*}{ Extension Units (\%) } & 4 & GC & $2.72 \pm 0.17$ \\
\hline & 5 & EGC & $2.30 \pm 0.22$ \\
\hline & 6 & $\mathrm{C}$ & $6.46 \pm 1.93$ \\
\hline & 7 & EC & $64.41 \pm 3.12$ \\
\hline & 8 & (E) CG & $2.59 \pm 0.53$ \\
\hline & 9 & A-type dimer & $0.78 \pm 0.08$ \\
\hline & 10 & (E) AF & $0.81 \pm 0.24$ \\
\hline Spatial & \multicolumn{2}{|c|}{$2^{\prime} 3$-cis configuration } & $79.13 \pm 0.85$ \\
\hline configuration $(\%)$ & \multicolumn{2}{|c|}{ 2'3-trans configuration } & $20.87 \pm 0.85$ \\
\hline \multicolumn{3}{|c|}{ Galloyl group (\%) } & $4.00 \pm 0.53$ \\
\hline \multicolumn{3}{|c|}{ A-type linkage (\%) } & $0.78 \pm 0.08$ \\
\hline \multicolumn{3}{|c|}{$\mathrm{mDP}$} & $5.02 \pm 0.21$ \\
\hline
\end{tabular}

C, EC, ECG, GC, EGC, (E)CG, and (E)AF were short for catechin, epicatechin, epicatechin gallate, gallocatechin, epigallocatechin, (epi)catechin gallate, and (epi)afzelechin, respectively.

\subsubsection{MALDI-TOF MS Analysis}

In this study, ${ }^{13} \mathrm{C}$ NMR and RP-HPLC-ESI-MS were used to obtain the monomer types, the composition of terminal units and extension units, the $\mathrm{mDP}$, the spatial configuration, and the substituents of the monomers of proanthocyanidins in the 70\% acetone eluent of the rhizome of $F$. dibotrys. On this basis, MALDI-TOF MS was used to analyze the distribution of polymeric proanthocyanidins and the linkage types of these polymeric proanthocyanidins, and more comprehensive and detailed structural information was obtained [31-33].

Further, after adequate deionization, the cationic reagent $\mathrm{CS}^{+}$was introduced, and DHB was used as the matrix to obtain a clear MALDI-TOF MS spectrum of proanthocyanidins in the $70 \%$ acetone eluent of the rhizome of $F$. dibotrys in reflection mode as shown in Figure 5. According to the previous analysis results, proanthocyanidins in the $70 \%$ acetone eluent of the rhizome of $F$. dibotrys were mainly composed of (epi)catechin, (epi)gallocatechin, (epi)catechin gallate, (epi) afzelechin and A-type dimer composed of (epi)catechin monomers, according to the molecular weight of different monomers, the analytical equation for proanthocyanidins in the $70 \%$ acetone eluent of the rhizome of F. dibotrys was established as follows:

$$
[M+C s]^{+}=133+2+288 a+304 b+272 c+440 d-2 e
$$

In Equation (1), $m / z 133$ is the atomic mass of $\mathrm{CS}^{+}, m / z 2$ was the atomic mass of the two-terminal hydrogen atoms, a, b, c, d, and e represent the number of (epi)catechin $(\mathrm{m} / \mathrm{z}$ $288)$, (epi)gallocatechin $(m / z$ 304), (epi)afzelechin $(m / z 272)$, (epi)catechin gallate $(m / z 440)$, and A-type linkage respectively [33]. The theoretical [M $+\mathrm{Cs}]^{+}$calculated according to Equation (1) was consistent with the actual detected $[\mathrm{M}+\mathrm{Cs}]^{+}$, indicating that the established analytical equation was reasonable (Table 9). Based on the comprehensive analysis of the information in Figure 5 and Table 9, the distribution of polymeric proanthocyanidins from trimer $(\mathrm{m} / z$ 999) to undecamer $(\mathrm{m} / \mathrm{z} 3303)$ were detected in the $70 \%$ acetone eluent of the rhizome of $F$. dibotrys, and the strongest molecular ion peak came from one pentamer $(m / z$ 1575). The strongest molecular ion peak sequence from trimer to undecamer was $m / z$ 999-1287-1575-1863-2015-2303-2439-2727-3015-3303 and could be detected in the MALDI-TOF MS spectrum. There was a difference of 288 Da between the ion peak sequence of adjacent molecules, and $288 \mathrm{Da}$ just corresponded to one (epi)catechin monomer. 
According to Equation (1), the above molecular ion peak sequence corresponded to the proanthocyanidins molecules composed of 3-11 (epi)catechin monomers, respectively, which was consistent with the results of ${ }^{13} \mathrm{C}$ NMR analysis and RP-HPLC-ESI-MS analysis of the thiolytic degradation products [33].
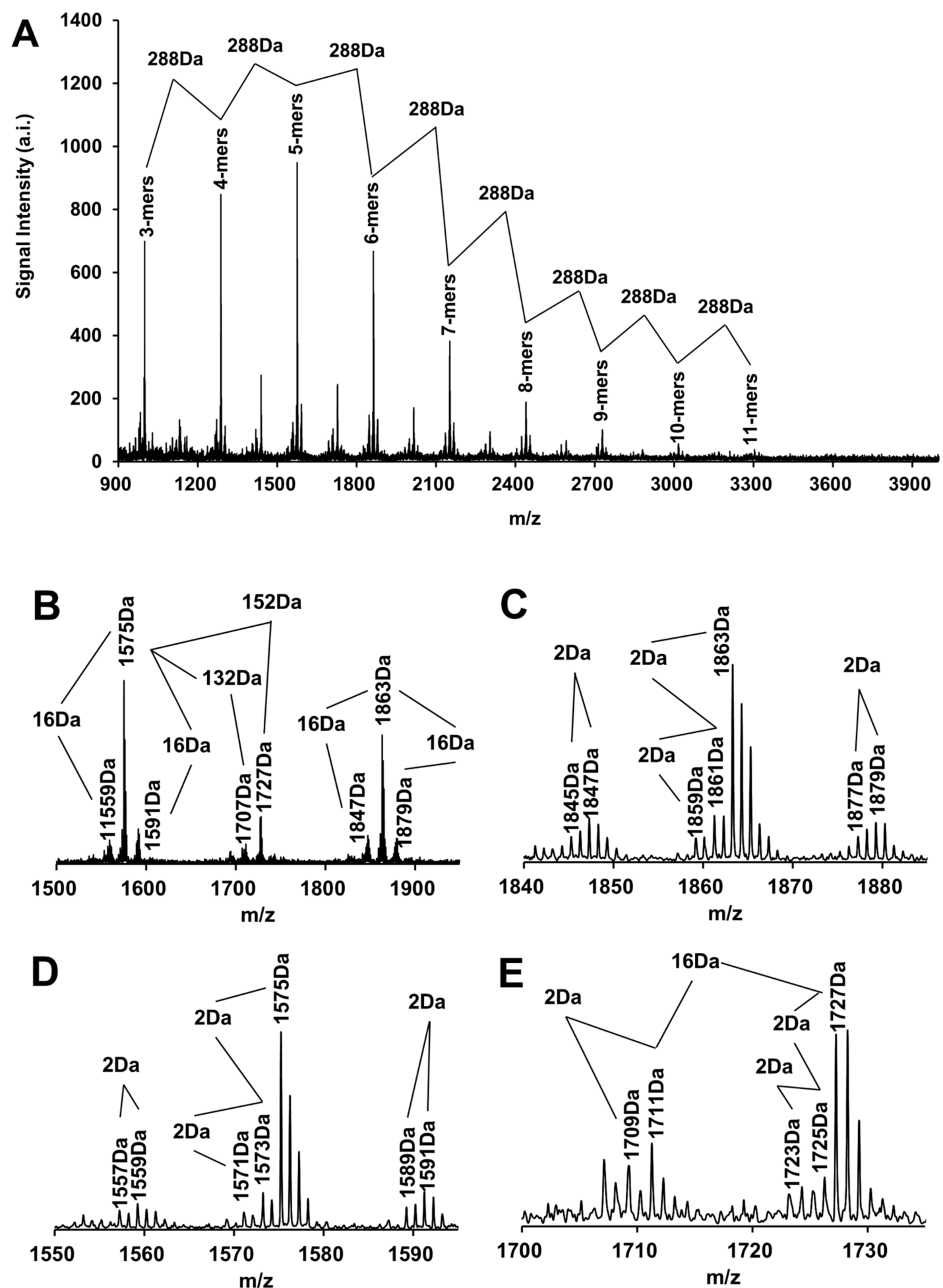

Figure 5. The MALDI-TOF MS spectrum of the $70 \%$ acetone eluent of the rhizome of $F$. dibotrys ((A) represents the spectrum of the ion peak in the range of $m / z$ 900-4000, while (B-E) represent the locally amplified spectrum). 
Table 9. MALDI-TOF MS analysis results of the $70 \%$ acetone eluent of the rhizome of $F$. dibotrys.

\begin{tabular}{|c|c|c|c|c|c|c|c|c|}
\hline No. & DP & (E)C & (E)GC & (E)AF & (E)CG & A-Type & $\begin{array}{c}\text { Cal } \\
{[\mathrm{M}+\mathrm{Cs}]^{+}}\end{array}$ & $\begin{array}{l}\text { Observed } \\
{[\mathrm{M}+\mathrm{Cs}]^{+}}\end{array}$ \\
\hline 1 & \multirow{9}{*}{ 3-mers } & 2 & 0 & 1 & 0 & 2 & 979 & 978.9893 \\
\hline 2 & & 2 & 0 & 1 & 0 & 1 & 981 & 981.0812 \\
\hline 3 & & 2 & 0 & 1 & 0 & 0 & 983 & 983.0591 \\
\hline 4 & & 3 & 0 & 0 & 0 & 2 & 995 & 995.0164 \\
\hline 5 & & 3 & 0 & 0 & 0 & 1 & 997 & 997.0663 \\
\hline 6 & & 3 & 0 & 0 & 0 & 0 & 999 & 999.0757 \\
\hline 7 & & 1 & 0 & 1 & 1 & 0 & 1135 & 1135.2317 \\
\hline 8 & & 2 & 0 & 0 & 1 & 1 & 1149 & 1149.1038 \\
\hline 9 & & 2 & 0 & 0 & 1 & 0 & 1151 & 1151.1265 \\
\hline 10 & \multirow{12}{*}{ 4-mers } & 3 & 0 & 1 & 0 & 1 & 1269 & 1269.1731 \\
\hline 11 & & 3 & 0 & 1 & 0 & 0 & 1271 & 1271.1989 \\
\hline 12 & & 4 & 0 & 0 & 0 & 2 & 1283 & 1283.0939 \\
\hline 13 & & 4 & 0 & 0 & 0 & 1 & 1285 & 1285.1801 \\
\hline 14 & & 4 & 0 & 0 & 0 & 0 & 1287 & 1287.1881 \\
\hline 15 & & 3 & 1 & 0 & 0 & 2 & 1299 & 1299.1941 \\
\hline 16 & & 3 & 1 & 0 & 0 & 1 & 1301 & 1301.1884 \\
\hline 17 & & 3 & 1 & 0 & 0 & 0 & 1303 & 1303.1790 \\
\hline 18 & & 2 & 0 & 1 & 1 & 0 & 1423 & 1423.2411 \\
\hline 19 & & 3 & 0 & 0 & 1 & 2 & 1435 & 1435.2147 \\
\hline 20 & & 3 & 0 & 0 & 1 & 1 & 1437 & 1437.1962 \\
\hline 21 & & 3 & 0 & 0 & 1 & 0 & 1439 & 1439.1993 \\
\hline 22 & \multirow{13}{*}{ 5-mers } & 4 & 0 & 1 & 0 & 1 & 1557 & 1557.2426 \\
\hline 23 & & 4 & 0 & 1 & 0 & 0 & 1559 & 1559.2617 \\
\hline 24 & & 5 & 0 & 0 & 0 & 2 & 1571 & 1571.1364 \\
\hline 25 & & 5 & 0 & 0 & 0 & 1 & 1573 & 1573.2393 \\
\hline 26 & & 5 & 0 & 0 & 0 & 0 & 1575 & 1575.2474 \\
\hline 27 & & 4 & 1 & 0 & 0 & 2 & 1587 & 1587.2273 \\
\hline 28 & & 4 & 1 & 0 & 0 & 1 & 1589 & 1589.2378 \\
\hline 29 & & 4 & 1 & 0 & 0 & 0 & 1591 & 1591.2358 \\
\hline 30 & & 3 & 0 & 1 & 1 & 1 & 1709 & 1709.2579 \\
\hline 31 & & 3 & 0 & 1 & 1 & 0 & 1711 & 1711.2736 \\
\hline 32 & & 4 & 0 & 0 & 1 & 2 & 1723 & 1723.2308 \\
\hline 33 & & 4 & 0 & 0 & 1 & 1 & 1725 & 1725.2627 \\
\hline 34 & & 4 & 0 & 0 & 1 & 0 & 1727 & 1727.2469 \\
\hline 35 & \multirow{14}{*}{ 6-mers } & 5 & 0 & 1 & 0 & 1 & 1845 & 1845.2870 \\
\hline 36 & & 5 & 0 & 1 & 0 & 0 & 1847 & 1847.2938 \\
\hline 37 & & 6 & 0 & 0 & 0 & 2 & 1859 & 1859.1938 \\
\hline 38 & & 6 & 0 & 0 & 0 & 1 & 1861 & 1861.2612 \\
\hline 39 & & 6 & 0 & 0 & 0 & 0 & 1863 & 1863.2898 \\
\hline 40 & & 5 & 1 & 0 & 0 & 1 & 1877 & 1877.2839 \\
\hline 41 & & 5 & 1 & 0 & 0 & 0 & 1879 & 1879.2777 \\
\hline 42 & & 3 & 0 & 2 & 1 & 1 & 1981 & 1981.3029 \\
\hline 43 & & 3 & 0 & 2 & 1 & 0 & 1983 & 1983.3977 \\
\hline 44 & & 4 & 0 & 1 & 1 & 1 & 1997 & 1997.1848 \\
\hline 45 & & 4 & 0 & 1 & 1 & 0 & 1999 & 1999.3131 \\
\hline 46 & & 5 & 0 & 0 & 1 & 2 & 2011 & 2011.2957 \\
\hline 47 & & 5 & 0 & 0 & 1 & 1 & 2013 & 2013.3037 \\
\hline 48 & & 5 & 0 & 0 & 1 & 0 & 2015 & 2015.2927 \\
\hline
\end{tabular}


Table 9. Cont.

\begin{tabular}{|c|c|c|c|c|c|c|c|c|}
\hline No. & DP & (E)C & (E)GC & (E)AF & (E)CG & A-Type & $\begin{array}{c}\text { Cal } \\
{[\mathrm{M}+\mathrm{Cs}]^{+}}\end{array}$ & $\begin{array}{l}\text { Observed } \\
\left.{ }_{[M+C s}\right]^{+}\end{array}$ \\
\hline 49 & \multirow{10}{*}{ 7-mers } & 6 & 0 & 1 & 0 & 1 & 2133 & 2133.3162 \\
\hline 50 & & 6 & 0 & 1 & 0 & 0 & 2135 & 2135.3201 \\
\hline 51 & & 7 & 0 & 0 & 0 & 2 & 2147 & 2147.2498 \\
\hline 52 & & 7 & 0 & 0 & 0 & 1 & 2149 & 2149.3015 \\
\hline 53 & & 7 & 0 & 0 & 0 & 0 & 2151 & 2151.3225 \\
\hline 54 & & 6 & 1 & 0 & 0 & 1 & 2165 & 2165.3149 \\
\hline 55 & & 6 & 1 & 0 & 0 & 0 & 2167 & 2167.3062 \\
\hline 56 & & 5 & 0 & 1 & 1 & 0 & 2287 & 2287.3433 \\
\hline 57 & & 6 & 0 & 0 & 1 & 1 & 2301 & 2301.3628 \\
\hline 58 & & 6 & 0 & 0 & 1 & 0 & 2303 & 2303.3269 \\
\hline 59 & \multirow{6}{*}{ 8-mers } & 7 & 0 & 1 & 0 & 0 & 2423 & 2423.3477 \\
\hline 60 & & 8 & 0 & 0 & 0 & 2 & 2435 & 2435.3259 \\
\hline 61 & & 8 & 0 & 0 & 0 & 1 & 2437 & 2437.3362 \\
\hline 62 & & 8 & 0 & 0 & 0 & 0 & 2439 & 2439.3589 \\
\hline 63 & & 7 & 1 & 0 & 0 & 0 & 2455 & 2455.3499 \\
\hline 64 & & 7 & 0 & 0 & 1 & 0 & 2591 & 2591.3704 \\
\hline 65 & \multirow{4}{*}{ 9-mers } & 8 & 0 & 1 & 0 & 0 & 2711 & 2711.3899 \\
\hline 66 & & 9 & 0 & 0 & 0 & 0 & 2727 & 2727.3938 \\
\hline 67 & & 8 & 1 & 0 & 0 & 0 & 2743 & 2743.3208 \\
\hline 68 & & 8 & 0 & 0 & 1 & 0 & 2879 & 2879.4021 \\
\hline 69 & \multirow{3}{*}{ 10-mers } & 9 & 0 & 1 & 0 & 0 & 2999 & 2999.4319 \\
\hline 70 & & 10 & 0 & 0 & 0 & 0 & 3015 & 3015.4089 \\
\hline 71 & & 9 & 1 & 0 & 0 & 0 & 3031 & 3031.4106 \\
\hline 72 & 11-mers & 11 & 0 & 0 & 0 & 0 & 3303 & 3303.4424 \\
\hline
\end{tabular}

(E)C, (E)GC, (E)AF, (E)CG, A-type and Cal [M + Cs $]^{+}$were short for (epi)catechin, (epi)gallocatechin, (epi)afzelechin, (epi)catechin gallate, A-type linkage, and calculated $[\mathrm{M}+\mathrm{Cs}]^{+}$, respectively.

In the locally amplified spectrum (Figure 5B), a series of molecular ion peaks with a $132 \mathrm{Da}$ difference from the strongest molecular ion peaks of adjacent polymers were detected. While $132 \mathrm{Da}$ represented the relative atomic mass of one $\mathrm{CS}^{+}$losing one proton, so these two groups of molecular ion peak sequences $\left[\mathrm{M}+2 \mathrm{Cs}^{+}-\mathrm{H}\right]$ and $\left[\mathrm{M}+\mathrm{Cs}^{+}-\mathrm{H}\right]$ corresponded to the same polymeric proanthocyanidins sequence [33]. Similarly, in the locally amplified spectrum (Figure 5B), a series of molecular ion peaks with a difference of 152 Da were detected between the strongest molecular ion peaks of the adjacent polymers. For example, the molecular ion peak sequence $m / z$ 1151-1439-1727-2015-2303-2591-2879 was 152 Da different from that of the molecular ion peak sequence $m / z$ 999-1287-1575-18632015-2303-2439-2707 respectively, and 152 Da was the relative molecular weight difference between one (epi)catechin gallate monomer $(\mathrm{m} / \mathrm{z} 440)$ and one (epi)catechin monomer $(\mathrm{m} / \mathrm{z}$ 288) [33]. In addition, molecular ion peak signals with a difference of $16 \mathrm{Da}$ from the main molecular ion peaks could be detected in the locally amplified spectrum (Figure 5B-E), such as those between $m / z$ 1559-1575-1591, $m / z$ 1711-1727, and $m / z$ 1847-1863-1879, and $16 \mathrm{Da}$ was the atomic mass of one oxygen atom, corresponding to the oxygen atom between (epi)afzelechin and (epi)catechin, or (epi)catechin and (epi)gallocatechin [33]. These results were consistent with the results of RP-HPLC-ESI-MS analysis of thiolytic degradation products, indicating that the presence of (epi)catechin gallate, (epi)gallocatechin, and (epi)afzelechin monomers of proanthocyanidins in the $70 \%$ acetone eluent of the rhizome of $F$. dibotrys could be detected by MALDI-TOF MS and could be directly demonstrated in the spectrum.

Two more hydrogen atoms were consumed when an A-type linkage was formed between two monomers by a C-C bond and a C-O-C bond than when a B-type linkage was formed between two monomers by only a $\mathrm{C}-\mathrm{C}$ bond, while $2 \mathrm{Da}$ corresponded to the atomic mass of two hydrogen atoms. Therefore, the existence of A-type linkage could be intuitively 
judged by analyzing the presence or absence of molecular ion peaks detected on MALDITOF MS spectrum with a 2 Da difference from the main molecular ion peaks [30-33]. Many molecular ion peaks signals with a 2Da difference from the main molecular ion peaks were detected from the locally amplified spectrum (Figure 5C-E), such as molecular ion peak sequences $m / z$ 1557-1559, $m / z$ 1571-1573-1575, $m / z$ 1589-1591, $m / z$ 1845-1847, m/z 1859$1861-1863, m / z 1877-1879$, as well as $m / z 1709-1711$, and $m / z 1723-1725-1727$, indicating that A-type linkages were prevalent in proanthocyanidins molecules of the $70 \%$ acetone eluent of the rhizome of $F$. dibotrys. For example, the molecular ion peak sequence $m / z$ 1571-15731575 represented three pentamers composed of five (epi)catechin monomers with two, one, and zero A-type linkage in their extension units, respectively. Previously, according to the RP-HPLC-ESI-MS analysis results of thiolytic degradation products, it was believed that the A-type linkage of proanthocyanidins in the $70 \%$ acetone eluent of the rhizome of $F$. dibotrys only existed in the extension units. Then, MALDI-TOF MS clearly detected the existence of A-type linkages and the number of A-type linkage in different proanthocyanidins molecules, indicating that different analytical methods used in this study could confirm each other, and the comprehensive use of various analytical methods was very helpful for obtaining more detailed structural information of proanthocyanidins [31-33].

\section{Materials and Methods}

\subsection{Materials and Reagents}

Seven species of common Polygonaceae plants, including Fagopyrum dibotrys [10,13,14], Fallopia multiflora [40,41], Polygonum aviculare [42-44], Polygonum orientale [45,46], Reynoutria japonica [11], Rheum officinale [12], and Rumex acetosa [47-50] were kindly supplied by Bozhou Chinese herbal medicine market in Anhui province (Anhui, China) and identified by Prof. Z.S. Liang, Northwest A\&F University. Then the rhizome of $F$. dibotrys, the shoots of F. dibotrys, the rhizome of F. multiflora, the shoots of F. multiflora, the whole plant of $P$. aviculare, the whole plant of $P$. orientale, the rhizome of $R$. japonica, the shoots of $R$. japonica, the rhizome of $R$. officinale, the shoots of $R$. officinale, the rhizome of $R$. acetosa and the shoots of $R$. acetosa were chosen as the experiment materials. Grape seed was selected as the control. All the samples were washed with deionized water, chopped, dried at $45^{\circ} \mathrm{C}$, crushed and sieved through 80 mesh, sealed and kept away from light at $-20^{\circ} \mathrm{C}$.

Deuterium dimethyl sulfoxide (DMSO- $d_{6}$ ), benzyl mercaptan, cesium chloride (purity $\geq 99.999 \%$ ), 2'5-dihydroxybenzoic acid (DHB), Dowex ${ }^{\circledR} 50 \mathrm{~W}$ X8 hydrogen strong acid cation exchange resin (200-400 mesh), chromatographic trifluoroacetic acid (TFA), catechin, epicatechin, gallocatechin, epigallocatechin, catechin gallate, epicatechin gallate, grape seed proanthocyanidins reference standard (GsPs), Saccharomyces cerevisiae $\alpha$-glucosidase (type I, from Saccharomyces cerevisiae), porcine pancreas $\alpha$-amylase (from porcine pancreas), human saliva $\alpha$-amylase (from human saliva), 2,2-diazo-bis(3-ethyl-benzothiazole-6-sulfonic acid) diammonium salt (ABTS), 6-hydroxy-2,5,7,8-tetramethylchromo-2-carboxylic acid (Trolox), 2,4,6-tripyridinyl-1,3,5-triazine (TPTZ), Vitamin C, 1,1-diphenyl-2-picrylhydrazyl (DPPH), Neocuproine hydrochloride monohydrate (NHCM), acarbose, and 4-nitrophenyl- $\alpha$-Dglucopyranoside ( $p$-NPG) were purchased from Sigma-Aldrich Chemical Co. (St. Louis, MO, USA). Sephadex LH-20 was purchased from GE Healthcare Bio-Sciences AB (Uppsala, Sweden). 2-choro-4-nitrophenyl- $\alpha$-galactosyl-maltoside (Gal- $\left.\mathrm{G}_{2}-\alpha-\mathrm{CNP}\right)$ was purchased from Toyobo Co., Ltd., (Osaka, Japan). Methanol, acetone, and acetonitrile, all with chromatographic purity, were purchased from Tedia (Fairfield, OH, USA). Potassium bromide and methanol, both of pure spectrum grade, were from Aladdin Reagents Co., Ltd. (Shanghai, China). Other reagents, including ferric chloride, potassium persulfate, copper sulfate, acetic acid, sodium acetate, petroleum ether, potassium dihydrogen phosphate, and dipotassium hydrogen phosphate, were of analytical grade and from Sinopharm Chemical Reagent Co., Ltd. (Shanghai, China). The water used in this study was deionized water. 


\subsection{Sample Preparation}

\subsubsection{Preparation of Plant Crude Extracts}

The powders of the seven species of Polygonaceae plant materials and grape seed were mixed with $85 \%$ methanol (volume fraction, the same below) at a solid-liquid ratio of 1:20 $(\mathrm{g} / \mathrm{L})$, and then stood for $12 \mathrm{~h}$ separately. Then the mixtures were extracted at $45^{\circ} \mathrm{C}$ with $500 \mathrm{~W}$ ultrasonic power for $40 \mathrm{~min}$ and then filtered. The filter residues were successively extracted with $70 \%$ methanol and $60 \%$ ethanol in accordance with the abovementioned parameters, and the filtrates were concentrated under reduced pressure at $45^{\circ} \mathrm{C}$ and $0.09 \mathrm{MPa}$ to recover the solvent. The concentrated solution of each sample was combined, then degreased with petroleum ether 5 times, and then lyophilized to obtain the crude extract of each sample, which were sealed at $-80^{\circ} \mathrm{C}$ and kept out of light [13].

\subsubsection{Isolation and Purification of Proanthocyanidins}

The crude extract of the rhizome of $F$. dibotrys was prepared from the rhizome of F. dibotrys powder according to the method described in Section 3.2.1. Seven and a half grams of the crude extract was fully dissolved in $50 \mathrm{~mL}$ of $50 \%$ methanol and then filtered by $0.45 \mu \mathrm{m}$ microporous membrane, and the filtrate was then enriched and purified by Sephadex LH-20. Sephadex LH-20 was fully swelled with 50\% methanol and then loaded into a glass chromatography column with a volume of $1.2 \mathrm{~L}$. The column was first balanced with $5 \mathrm{~L}$ of $50 \%$ degassed methanol, then the filtrate was carefully loaded, and the piston of the column was closed for adsorption for $6 \mathrm{~h}$. First, the column was eluted by $5 \mathrm{~L}$ of $50 \%$ degassed methanol at a rate of $1.0 \mathrm{~mL} / \mathrm{min}$; the eluent was collected and concentrated under reduced pressure at $45^{\circ} \mathrm{C}$ and $0.09 \mathrm{MPa}$, and then lyophilized to obtain the $50 \%$ methanol eluent. Then, the column was subsequently eluted by $2.5 \mathrm{~L}$ of $70 \%$ degassed acetone at a rate of $3.0 \mathrm{~mL} / \mathrm{min}$; the eluent was collected and concentrated under reduced pressure at $45^{\circ} \mathrm{C}$ and $0.09 \mathrm{MPa}$ and then lyophilized to obtain the $70 \%$ acetone eluent [33].

\subsubsection{Preparation of Sample Solution}

The crude extracts of the seven species of Polygonaceae plant materials and grape seed were fully dissolved in $10 \%$ DMSO to obtain a solution equivalent to $10 \mathrm{mg} \mathrm{DW} / \mathrm{mL}$. Then all the solutions were filtered by a $0.45 \mu \mathrm{m}$ microporous membrane and diluted into solutions equivalent to $10 \mu \mathrm{g} \mathrm{DW} / \mathrm{mL}$ with $\mathrm{NaH}_{2} \mathrm{PO}_{4}-\mathrm{Na}_{2} \mathrm{HPO}_{4}$ buffer $(100 \mathrm{mM}$, $\mathrm{pH}=6.86)$ to determine their inhibitory activity against $S$. cerevisiae $\alpha$-glucosidase; and diluted into solutions equivalent to $100 \mu \mathrm{g} \mathrm{DW} / \mathrm{mL}$ with $\mathrm{NaH}_{2} \mathrm{PO}_{4}-\mathrm{Na}_{2} \mathrm{HPO}_{4}$ buffer $(100 \mathrm{mM}, \mathrm{pH}=6.86$, containing $6.7 \mathrm{mM} \mathrm{NaCl})$ to determine their inhibitory activities against porcine pancreatic $\alpha$-amylase and human salivary $\alpha$-amylase [4,51]. Crude extract, the $50 \%$ methanol eluent, and the $70 \%$ acetone eluent of the rhizome of $F$. dibotrys were fully dissolved in $10 \%$ DMSO to obtain solutions equivalent to $10 \mathrm{mg} \mathrm{DW} / \mathrm{mL}$, filtrated, and then diluted with the corresponding buffer to their most suitable concentration of each to determine their half inhibitory concentrations $\left(\mathrm{IC}_{50}\right.$ values) against $S$. cerevisiae $\alpha$-glucosidase, porcine pancreatic $\alpha$-amylase, and human salivary $\alpha$-amylase.

The crude extracts of the seven species of Polygonaceae plant materials and grape seed were fully dissolved in $80 \%$ methanol to obtain solutions equivalent to $10 \mathrm{mg} \mathrm{DW} / \mathrm{mL}$. Then all the solutions were filtered by a $0.45 \mu \mathrm{m}$ microporous membrane and diluted into solutions equivalent to $500 \mu \mathrm{g} \mathrm{DW} / \mathrm{mL}$ with methanol to determine the DPPH and ABTS free radical scavenging rates of each sample and diluted with methanol to their most suitable concentration to determine their total proanthocyanidins content (TOPCs), Ferric ion reducing antioxidant power (FRAP) and Cupric ion reducing power (CUPRAC). Crude extract, the $50 \%$ methanol eluent, and the $70 \%$ acetone eluent of the rhizome of $F$. dibotrys were fully dissolved in $80 \%$ methanol to obtain solutions equivalent to $10 \mathrm{mg} \mathrm{DW} / \mathrm{mL}$, filtrated, and then diluted with methanol to their most suitable concentration of each to determine their TOPCs, their half scavenging concentrations ( $\mathrm{EC}_{50}$ values) against $\mathrm{DPPH}$ and ABTS free radical, and their FRAP and CUPRAC values. 


\subsection{Determination of Total Proanthocyanidins Content (TOPCs)}

GsPs was selected as the control, $200 \mu \mathrm{L}$ of GsPs solution of different concentrations was added into a glass test tube, followed by $7500 \mu \mathrm{L}$ of HCl-n-butanol solution (with a volume ratio of 5:95) and $100 \mu \mathrm{L}$ of $2 \%$ ammonium ferric sulfate solution $(2 \mathrm{M} \mathrm{HCl}$ as the solvent). After fully mixing, the test tube was placed in boiling water for $75 \mathrm{~min}$ and then cooled by ice bath immediately. When the temperature was restored to room temperature, the absorbance value at $550 \mathrm{~nm}\left(\mathrm{~A}_{550}\right)$ was measured on a UV-1700 UV-Visible Spectrophotometer (Shimadzu, Kyoto, Japan) with distilled water as blank. The standard curve was drawn with the concentration of GsPs as the $X$-axis and the absorbance as the $Y$-axis, and the linear regression equation $Y=0.9933 X-0.0045\left(R^{2}=0.9998\right)$ was obtained, with the linear range of $0.00-1.00 \mathrm{mg} / \mathrm{mL}$. The solution of each sample was diluted with methanol to their appropriate concentration so that the absorbance value at $550 \mathrm{~nm}$ was between 0.200 and 0.800 . The $A_{550}$ value of each sample was determined respectively, and the TOPCs of each sample were calculated according to the linear regression equation and expressed as the equivalent value of each sample to GsPs (mg GsPs/g DW) [36,37].

\subsection{Antioxidant Assay}

\subsubsection{DPPH Assay}

DPPH free radical solution was prepared with methanol with a concentration of $100 \mu \mathrm{M}$. One hundred microliters of the sample solution was thoroughly mixed with $3000 \mu \mathrm{L}$ of DPPH free radical solution, and the absorbance value $\left(\mathrm{A}_{517}\right)$ at $517 \mathrm{~nm}$ was determined on a UV-1700 UV-Visible Spectrophotometer after reaction in the dark place at room temperature for $30 \mathrm{~min}$, with methanol as blank. DPPH free radical scavenging rates of samples with different concentrations were calculated according to Formula (2):

$$
\mathrm{DPPH} \text { free radical scavenging rate } \%=\left(\mathrm{A}_{0}-\mathrm{A}_{\mathrm{i}}\right) / \mathrm{A}_{0} \times 100
$$

In Formula (2), $A_{0}$ and $A_{i}$ respectively represent the absorbance values of blank samples (methanol) and sample solutions of different concentrations after reacting with DPPH free radical solution. The DPPH free radical scavenging activities of the seven species of Polygonaceae plant materials and grape seed were expressed as the DPPH scavenging rates of each sample at the concentration of $500 \mu \mathrm{g} D W / \mathrm{mL}$. According to the pre-test results, sample solutions of crude extract, $50 \%$ methanol eluent, and $70 \%$ acetone eluent of the rhizome of $F$. dibotrys were diluted with methanol into eight appropriate concentration gradients of each so that the DPPH free radical scavenging rate of each sample under the maximum concentration was $\geq 80 \%$. The DPPH free radical scavenging activity of each sample was represented by the half scavenging concentration of DPPH free radical $\left(\mathrm{EC}_{50}\right.$ value) of the sample. GsPs and Vc were selected as the control substances, and the smaller $\mathrm{EC}_{50}$ value meant the stronger DPPH free radical scavenging activity [31-33,52].

\subsubsection{ABTS Assay}

ABTS free radical was prepared by the reaction of ABTS aqueous solution with potassium persulfate, and ABTS free radical was diluted with ethanol to a solution with an absorbance value of about $0.700 \pm 0.020$ at $734 \mathrm{~nm}$ [40]. The sample solution of $100 \mu \mathrm{L}$ was thoroughly mixed with ABTS free radical solution of $3000 \mu \mathrm{L}$, and the absorbance value $\left(\mathrm{A}_{734}\right)$ at $734 \mathrm{~nm}$ was determined on a UV-1700 UV-Visible Spectrophotometer after reaction in the dark place at room temperature for $30 \mathrm{~min}$, with methanol as blank. ABTS free radical scavenging rates of samples with different concentrations were calculated according to Formula (3):

ABTS free radical scavenging rate $\%=\left(\mathrm{A}_{0}-\mathrm{A}_{\mathrm{i}}\right) / \mathrm{A}_{0} \times 100$

In Formula (3), $A_{0}$ and $A_{i}$ respectively represent the absorbance values of blank samples (methanol) and sample solutions of different concentrations after reacting with ABTS free radical solutions. The ABTS free radical scavenging activities of the seven species 
of Polygonaceae plant materials and grape seed were expressed as the ABTS scavenging rates of each sample at the concentration of $500 \mu \mathrm{g}$ DW $/ \mathrm{mL}$. According to the pre-test results, sample solutions of crude extract, $50 \%$ methanol eluent, and $70 \%$ acetone eluent of the rhizome of $F$. dibotrys were diluted with methanol into eight appropriate concentration gradients of each so that the ABTS free radical scavenging rate of each sample under the maximum concentration was $\geq 80 \%$. The ABTS free radical scavenging activity of each sample was represented by the half scavenging concentration of ABTS free radical $\left(\mathrm{EC}_{50}\right.$ value) of the sample. GsPs and Vc were selected as the control substances, and the smaller $\mathrm{EC}_{50}$ value meant the stronger ABTS free radical scavenging activity [53].

\subsubsection{FRAP Assay}

The FRAP reagent was prepared by mixing acetic acid-sodium acetate buffer $(300 \mathrm{mM}$, $\mathrm{pH}=3.6)$, TPTZ solution $(10 \mathrm{mM}, 40 \mathrm{mM} \mathrm{HCl}$ as the solvent $)$ and $\mathrm{FeCl}_{3}$ aqueous solution $(20 \mathrm{mM})$ in a 10:1:1 volume ratio [42]. One hundred microliters of Vc solution of different concentrations were added into a test tube, followed by $3000 \mu \mathrm{L}$ of FRAP reagent, and thoroughly mixed. After reaction at room temperature for $30 \mathrm{~min}$, the absorbance value $\left(\mathrm{A}_{593}\right)$ of the solution at $593 \mathrm{~nm}$ was determined on a UV-1700 UV-Visible Spectrophotometer with distilled water as blank. Taking the concentration of Vc solution as the X-axis and the absorbance as the $Y$-axis, the standard curve was drawn, and the linear regression equation was $Y=14.3510 X+0.0670\left(R^{2}=0.9996\right)$, with a linear range of $0.00-0.15 \mathrm{mg} / \mathrm{mL}$. The solution of each sample was diluted with methanol to an appropriate concentration so that the absorbance value at $593 \mathrm{~nm}$ was between 0.200 and 0.800 . The $\mathrm{A}_{593}$ value of each sample was determined respectively, and the FRAP value of each sample was calculated according to the linear regression equation and expressed as the equivalent value of each sample to $\mathrm{Vc}_{\mathrm{c}}(\mathrm{mg} \mathrm{Vc} / \mathrm{g}$ equivalent) [31,54].

\subsubsection{CUPRAC Assay}

One hundred microliters of Trolox solution of different concentrations were added into a test tube, and then $1000 \mu \mathrm{L}$ of $5 \mathrm{mM} \mathrm{CuSO}_{4}$ aqueous solution, $1000 \mu \mathrm{L}$ of $1 \mathrm{M}$ aceto-ammonium acetate buffer, $1000 \mu \mathrm{L}$ of $3.75 \mathrm{mM}$ NHCM ethanol solution, and $1000 \mu \mathrm{L}$ of distilled water were added into the same test tube successively and thoroughly mixed. After reaction at room temperature for $30 \mathrm{~min}$, the absorbance value $\left(\mathrm{A}_{450}\right)$ of the solution at $450 \mathrm{~nm}$ was determined on a UV-1700 UV-Visible Spectrophotometer with distilled water as blank. Taking the concentration of Trolox solution as the $X$-axis and the absorbance as the $Y$-axis, the standard curve was drawn, and the linear regression equation was $Y=1.7501 \mathrm{X}$ $+0.0032\left(R^{2}=0.9992\right)$, with a linear range of $0.00-0.40 \mathrm{mg} / \mathrm{mL}$. The solution of each sample was diluted with methanol to an appropriate concentration so that the absorbance value at $450 \mathrm{~nm}$ was between 0.200 and 0.800 . The $\mathrm{A}_{450}$ value of each sample was determined respectively, and the CUPRAC value of each sample was calculated according to the linear regression equation and expressed as the equivalent value of each sample to Trolox (mg Trolox/g equivalent) [55].

\subsection{Antidiabetic Assay}

$p$-NPG was used as a substrate for $S$. cerevisiae $\alpha$-glucosidase, and $\mathrm{Gal}_{-} \mathrm{G}_{2}-\alpha-\mathrm{CNP}$ was used as a substrate for porcine pancreatic $\alpha$-amylase and human salivary $\alpha$-amylase. $\mathrm{NaH}_{2} \mathrm{PO}_{4}-\mathrm{Na}_{2} \mathrm{HPO}_{4}$ buffer solution $(100 \mathrm{mM}, \mathrm{pH}=6.86)$ was prepared, and the buffer solution was used as the solvent to prepare the S. cerevisiae $\alpha$-glucosidase solution with the concentration of $100 \mathrm{U} / \mathrm{L}$ and substrate solution with the concentration of $5 \mathrm{mM}$, respectively. $\mathrm{NaH}_{2} \mathrm{PO}_{4}-\mathrm{Na}_{2} \mathrm{HPO}_{4}$ buffer $(50 \mathrm{mM}, \mathrm{pH}=6.86$, containing $6.7 \mathrm{mM} \mathrm{NaCl})$ was prepared, and the buffer was used as a solvent to prepare the porcine pancreatic $\alpha$-amylase with the concentration of $1250 \mathrm{U} / \mathrm{L}$ and human salivary $\alpha$-amylase with the concentration of $2500 \mathrm{U} / \mathrm{L}$ and substrate solution with the concentration of $5 \mathrm{mM}$, respectively. $50 \mu \mathrm{L}$ of buffer solution, $50 \mu \mathrm{L}$ of enzyme solution, and $50 \mu \mathrm{L}$ of sample solution were successively added into each well of a 96-well plate and thoroughly mixed. After incubated at $37^{\circ} \mathrm{C}$ for 
$10 \mathrm{~min}, 50 \mu \mathrm{L}$ of substrate solution was added into each well and thoroughly mixed, and the increase in absorbance at $405 \mathrm{~nm}\left(\Delta_{405}\right)$ within 15 min was recorded on a SpectraMax M2 Microplate Reader (Molecular Devices, California, USA). The enzyme inhibition rates of samples with different concentrations were calculated according to Formula (4):

$$
\text { enzyme inhibition rate } \%=\left(\Delta_{0}-\Delta_{\mathrm{i}}\right) / \Delta_{0} \times 100
$$

In Formula (4), $\Delta_{0}$ and $\Delta_{\mathrm{i}}$ respectively represent the increase in absorbance at $405 \mathrm{~nm}$ after the blank sample (buffer) and sample solutions with different concentrations interacted with the enzyme-substrate system. The inhibitory activities of the seven species of Polygonaceae plant materials and grape seed against $S$. cerevisiae $\alpha$-glucosidase were expressed as the inhibition rates of each sample at the concentration of $10 \mu \mathrm{g} \mathrm{DW} / \mathrm{mL}$, and the inhibitory activities of the seven species of Polygonaceae plant materials and grape seed against porcine pancreatic $\alpha$-amylase and human salivary $\alpha$-amylase were expressed as the inhibition rates of each sample at the concentration of $100 \mu \mathrm{g} \mathrm{DW} / \mathrm{mL}$. According to the pre-test results, sample solutions of crude extract, the $50 \%$ methanol eluent, and the $70 \%$ acetone eluent of the rhizome of $F$. dibotrys were diluted with buffer solution into eight appropriate concentration gradients of each so that the enzymatic inhibition rate of each sample under the maximum concentration was $\geq 80 \%$. The enzymatic inhibitory activity of each sample was represented by the half inhibition concentration of each enzyme $\left(\mathrm{IC}_{50}\right.$ value) of the sample. GsPs and acarbose were selected as the control substances, and the smaller $\mathrm{IC}_{50}$ value meant the stronger enzymatic inhibitory activity $[2-5,51]$.

\subsection{Structure Analysis of Proanthocyanidins}

\subsubsection{UV-Vis Analysis}

The $70 \%$ acetone eluent of the rhizome of F. dibotrys and GsPs were prepared with methanol at a concentration of $50 \mu \mathrm{g} / \mathrm{mL}$, respectively. The absorption spectrum of the samples was drawn at 200-400 nm after blank scanning with methanol on a UV-1700 UV-visible spectrophotometer to obtain the UV spectrum of the samples [4]. Then the 70\% acetone eluent of the rhizome of F. dibotrys and GsPs were prepared with methanol at a concentration of $1.00 \mathrm{mg} / \mathrm{mL}$, respectively. After color development according to the method described in Section 3.3, the absorption spectrum of the samples was drawn at 400-800 nm after blank scanning with distilled water on a UV-1700 UV-visible spectrophotometer to obtain the visible spectrum of the samples [36].

\subsubsection{FT-IR Analysis}

The $70 \%$ acetone eluent of the rhizome of F. dibotrys and GsPs were mixed with potassium bromide after fully drying and pressed into tablets. The FT-IR spectrum in the wave number range of $4000-400 \mathrm{~cm}^{-1}$ were plotted by a Nicolet IS 5 FT-IR Spectrometer (Thermo Scientific, San Jose, CA, USA) with potassium bromide as blank scanning. The scanning resolution and scanning times were set to $4 \mathrm{~cm}^{-1}$ and 32 times [4].

\subsection{3. ${ }^{13} \mathrm{C}$ NMR Analysis}

One hundred and twenty-five micrograms of the $70 \%$ acetone eluent of the rhizome of F. dibotrys and GsPs were dissolved in $600 \mu \mathrm{L}$ of DMSO- $d_{6}$ separately, and the ${ }^{13} \mathrm{C}$ NMR spectrum was collected by a Bruker nuclear magnetic resonance spectrometer (Avance III 500, Bruker, Karlsruhe, Germany). The scanning frequency, pulse angle, and delay time were $126 \mathrm{MHz}, 45^{\circ}$, and $3 \mathrm{~s}$, respectively [32].

3.6.4. Benzyl Mercaptan Degradation of Proanthocyanidins and RP-HPLC-ESI-MS Analysis of Thiolytic Degradation Products

Five micrograms of the $70 \%$ acetone eluent of the rhizome of $F$. dibotrys were dissolved in $1 \mathrm{~mL}$ of methanol and fully mixed with $1 \mathrm{~mL}$ of $3.3 \%(v / v)$ of $\mathrm{HCl}$-methanol solution and $2 \mathrm{~mL}$ of $5 \%(v / v)$ of benzyl mercaptan-methanol solution. The degradation products were 
obtained by reaction at $40{ }^{\circ} \mathrm{C}$ for $30 \mathrm{~min}$ and filtered by $0.22 \mu \mathrm{m}$ microporous membrane for analysis [33].

The RP-HPLC analysis was performed on a Waters 1525 binary high-performance liquid chromatograph system with Waters XBridge Beh Shield RP18 (130 ̊, $5 \mu \mathrm{m}, 4.6 \mathrm{~mm}$ $\times 250 \mathrm{~mm}$ ) column and Waters 2996 photodiode array detector (Waters, Milford, MA, USA). Mobile phase A and B were acetonitrile and $0.5 \%(v / v)$ TFA aqueous solution, respectively, and the elution gradient was $0-45 \mathrm{~min}, 12 \%-80 \% \mathrm{~A} ; 45-50 \mathrm{~min}, 80 \%-12 \%$ A. The injection volume was $20 \mu \mathrm{L}$, the flow rate was $1.0 \mathrm{~mL} / \mathrm{min}$, the column temperature was $25^{\circ} \mathrm{C}$, and the detection wavelength was $280 \mathrm{~nm}$.

The ESI-MS analysis was performed on an LTQ-XL linear ion trap mass spectrometer (Thermo Scientific, San Jose, CA, USA) with a split ratio of 1:3, a capillary temperature of $400{ }^{\circ} \mathrm{C}$, an electrospray voltage of $4.50 \mathrm{kV}$, a sheath gas pressure of $50 \mathrm{psi}$, an auxiliary gas pressure of $10 \mathrm{psi}$, an intra source collision-induced disintegration energy of $10 \mathrm{~V}$ and collision energy of $50 \mathrm{~V}$, and a negative ion scanning range of $m / z$ 100-800.

The thiolytic degradation products of the $70 \%$ acetone eluent of the rhizome of $F$. dibotrys were identified by the chromatographic retention time, and the mass spectrum data and the mean degree of polymerization (mDP) were calculated according to formula (4) proposed by Zhou et al. [33]:

$\mathrm{mDP}=1+$ total peak area of extension units/total peak area of terminal units

\subsubsection{MALDI-TOF MS Analysis}

According to the method of Zhou et al. [33], the 70\% acetone eluent of the rhizome of F. dibotrys was prepared with $30 \%(v / v)$ acetone-water solution into a $10 \mathrm{mg} / \mathrm{mL}$ solution and deionized with Dowex ${ }^{\circledR} 50 \mathrm{~W}$ X8 resin. After that, the sample was fully mixed with $\mathrm{CsCl}(1.52 \mathrm{mg} / \mathrm{mL}$ aqueous solution) and DHB $(10 \mathrm{mg} / \mathrm{mL}, 30 \%(v / v)$ acetone-water solution as the solvent) at a volume ratio of 1:1:6. Then $1.0 \mu \mathrm{L}$ of the mixture were sampled onto the target and dried at room temperature for analysis by a MALDI-TOF MS analyzer (ABI 4700 MALDI-TOF/TOF, Waltham, MA, USA). The target was calibrated using external standards Angiotensin II (1046.5 Da), Bombesin (1619.8 Da), Acthclip 18-39 (2465.2 Da), and Somatostatin 28 ( $3147.47 \mathrm{Da}$ ) before analysis. The analytical parameters were as follows: the wavelength of $\mathrm{N}_{2}$ laser was $337 \mathrm{~nm}$, the pulse width was $3 \mathrm{~ns}$, the acceleration and reflection voltage of reflection mode analysis were $20.0 \mathrm{kV}$ and $23.0 \mathrm{kV}$, respectively, the optimal mass resolution was $2000 \mathrm{Da}$, the positive ion scanning range was $m / z 900-4000 \mathrm{Da}$, and the number of scanning was 200-500 times.

\subsection{Statistical Analysis}

All data measurements in this study were repeated 3 times, and the results were expressed as Mean $\pm \mathrm{SD}$. One-way analysis of variance (One-way ANVOA) and Student's $t$ test were performed using the SPSS22.0 software (SPSS Inc., Chicago, IL, USA), and $p<0.05$ was considered to be statistically significant.

\section{Conclusions}

The results of this study indicated that proanthocyanidins were the main antioxidant and antidiabetic active substances in the rhizome of $F$. dibotrys, and proanthocyanidins purified from the rhizome of $F$. dibotrys showed similar antioxidant activity to GsPs and stronger antidiabetic activity than GsPs. Proanthocyanidins were identified from the 70\% acetone eluent in the rhizome of $F$. dibotrys, and their structures were characterized with catechin and epicatechin accounted for more than $90 \%$ of all monomers and the $\mathrm{mDP}$ was about $5.02 \pm 0.21$. This study is expected to provide guidance and reference for the development of $F$. dibotrys as a potential antioxidant and hypoglycemic product. However, for further elucidate the mechanism of antioxidant and antidiabetes of F. dibotrys, and to better and more safely exploit and utilize the plant resources of $F$. dibotrys, enough cells, animals, and clinical trials are essential. 
Supplementary Materials: Figure S1: The Chemical structure of typical flavane-3-ol monomers. Table S1: The abbreviations in this article. A brief introduction of the seven Polygonaceae plants used in this article is also available in the Supplementary Materials.

Author Contributions: Methodology, X.L., J.L., and X.L.; validation, X.L. and Z.Z.; formal analysis, X.L. and Q.C.; investigation, X.L. and Z.L.; resources, X.L. and J.L.; data curation, X.L. and J.L.; writing-original draft preparation, X.L., J.L., and Z.Z.; writing-review and editing, X.L., Q.C., and R.H.; supervision, Z.L.; project administration, R.H.; funding acquisition, Z.L. All authors have read and agreed to the published version of the manuscript.

Funding: This research was funded by the Key Research and Development Program in Shaanxi Province, China (2017TSCL-SF-11-2, 2019TSLSF02-02, and 2020ZDLSF05-02).

Institutional Review Board Statement: Not applicable.

Informed Consent Statement: Not applicable.

Data Availability Statement: Not applicable.

Conflicts of Interest: The authors declare no conflict of interest.

Sample Availability: The proanthocyanidins purified from the rhizome of F. dibotrys are available from the authors.

\section{References}

1. Mancini, F.R.; Affret, A.; Dow, C.; Balkau, B.; Bonnet, F.; Boutron-Ruault, M.-C.; Fagherazzi, G. Dietary antioxidant capacity and risk of type 2 diabetes in the large prospective E3N-EPIC cohort. Diabetologia 2018, 61, 308-316. [CrossRef] [PubMed]

2. Schäfer, A.; Högger, P. Oligomeric procyanidins of French maritime pine bark extract (Pycnogenol ${ }^{\text {) }}$ ) effectively inhibit $\alpha$ glucosidase. Diabetes Res. Clin. Pr. 2007, 77, 41-46. [CrossRef] [PubMed]

3. Wang, H.; Liu, T.; Song, L.; Huang, D. Profiles and $\alpha$-Amylase Inhibition Activity of Proanthocyanidins in Unripe Manilkara zapota (Chiku). J. Agric. Food Chem. 2012, 60, 3098-3104. [CrossRef] [PubMed]

4. Fu, C.; Yang, X.; Lai, S.; Liu, C.; Huang, S.; Yang, H. Structure, antioxidant and $\alpha$-amylase inhibitory activities of longan pericarp proanthocyanidins. J. Funct. Foods 2015, 14, 23-32. [CrossRef]

5. Lu, Y.; Demleitner, M.F.; Song, L.; Rychlik, M.; Huang, D. Oligomeric proanthocyanidins are the active compounds in Abelmoschus esculentus Moench for its $\alpha$-amylase and $\alpha$-glucosidase inhibition activity. J. Funct. Foods 2016, 20, 463-471. [CrossRef]

6. Aron, P.M.; Kennedy, J.A. Flavan-3-ols: Nature, occurrence and biological activity. Mol. Nutr. Food Res. 2008, 52, 79-104. [CrossRef]

7. De La Iglesia, R.; Milagro, F.I.; Campión, J.; Boqué, N.; Martínez, J.A. Healthy properties of proanthocyanidins. BioFactors 2010, 36, 159-168. [CrossRef]

8. Manach, C.; Scalbert, A.; Morand, C.; Rémésy, C.; Jiménez, L. Polyphenols: Food sources and bioavailability. Am. J. Clin. Nutr. 2004, 79, 727-747. [CrossRef]

9. Kraus, T.E.C.; Yu, Z.; Preston, C.M.; Dahlgren, R.A.; Zasoski, R.J. Linking Chemical Reactivity and Protein Precipitation to Structural Characteristics of Foliar Tannins. J. Chem. Ecol. 2003, 29, 703-730. [CrossRef]

10. Jing, R.; Li, H.-Q.; Hu, C.-L.; Jiang, Y.-P.; Qin, L.-P.; Zheng, C.-J. Phytochemical and Pharmacological Profiles of Three Fagopyrum Buckwheats. Int. J. Mol. Sci. 2016, 17, 589. [CrossRef]

11. Zhao, Y.; Chen, M.X.; Kongstad, K.T.; Jäger, A.K.; Staerk, D. Potential of Polygonum cuspidatum Root as an Antidiabetic Food: Dual High-Resolution $\alpha$-Glucosidase and PTP1B Inhibition Profiling Combined with HPLC-HRMS and NMR for Identification of Antidiabetic Constituents. J. Agric. Food Chem. 2017, 65, 4421-4427. [CrossRef] [PubMed]

12. Kongstad, K.T.; Özdemir, C.; Barzak, A.; Wubshet, S.G.; Staerk, D. Combined Use of High-Resolution $\alpha$-Glucosidase Inhibition Profiling and High-Performance Liquid Chromatography-High-Resolution Mass Spectrometry-Solid-Phase Extraction-Nuclear Magnetic Resonance Spectroscopy for Investigation of Antidiabetic Principles in Crude Plant Extracts. J. Agric. Food Chem. 2015, 63, 2257-2263. [CrossRef]

13. Cai, Y.-Z.; Sun, M.; Xing, J.; Luo, Q.; Corke, H. Structure-radical scavenging activity relationships of phenolic compounds from traditional Chinese medicinal plants. Life Sci. 2006, 78, 2872-2888. [CrossRef]

14. Quettier-Deleu, C.; Gressier, B.; Vasseur, J.; Dine, T.; Brunet, C.; Luyckx, M.; Cazin, M.; Cazin, J.-C.; Bailleul, F.; Trotin, F. Phenolic compounds and antioxidant activities of buckwheat (Fagopyrum esculentum Moench) hulls and flour. J. Ethnopharmacol. 2000, 72, 35-42. [CrossRef]

15. El-Seedi, H.R.; Khalifa, S.A.; Yosri, N.; Khatib, A.; Chen, L.; Saeed, A.; Efferth, T.; Verpoorte, R. Plants mentioned in the Islamic Scriptures (Holy Qur'ân and Ahadith): Traditional uses and medicinal importance in contemporary times. J. Ethnopharmacol. 2019, 243, 112007. [CrossRef] [PubMed]

16. Krkošková, B.; Mrázová, Z. Prophylactic components of buckwheat. Food Res. Int. 2005, 38, 561-568. [CrossRef] 
17. Shao, M.; Yang, Y.H.; Gao, H.Y.; Wu, B.; Wang, L.B.; Wu, L.J. Studies on the chemical constituents of Fagopyrum dibotrys. J. Shenyang Pharm. Univ. 2005, 22, 100-102. [CrossRef]

18. Bai, Z.Z.; Zhang, X.H.; Xuan, L.J.; Mo, F.K. A phenolic glycoside from Fagopyrum dibotrys (D. Don) Hara. Chin. Chem. Lett. 2007, 18, 1087-1088. [CrossRef]

19. Wu, H.Z.; Zhou, J.Y.; Pan, H.L. Study on chemical constituents of Fagopyrum dibotrys (D. Don) Hara. Chin. J. Hosp. Pharm. 2008, 28, 21-26. [CrossRef]

20. Guo, X.N.; Yao, H.Y. Anti-proliferative effect of tartary buckwheat protein fraction TBWSP31 on breast cancer cells. Food Sci. 2010, 31, 317-320. [CrossRef]

21. Sun, G.J.; Cui, T.H.; Jin, Q.K.; Li, X.D.; Li, S.J.; Cui, C.B. Cytotoxicity of different extract parts of buckwheat sprout. Food Sci. Technol. 2012, 10, 200-203. [CrossRef]

22. Guo, L.; Zhao, Z.Y.; Han, S.Y. Studies on antitumor activities of extraction from buckwheat flower and leaf in vitro and its mechanism. Pharmacol. Clin. Chin. Mater. Med. 2013, 29, 50-52. [CrossRef]

23. Guo, L.; Zhao, Z.Y.; Han, S.Y. Study on antioxidative and antitumor effect of extraction of buckwheat flower and leaf. China J. Exp. Tradit. Med. Formul. 2012, 18, 176-179. [CrossRef]

24. Sheng, Y.T.; Xu, F.; Ruan, Q.X. Effects of tartary wheet flavone on neurofunction in diabetic rats. Pract. Pharm. Clin. Remedies 2006, 9, 219-221. [CrossRef]

25. Han, G.; Yao, G.X.; Lin, Q.H.; Zhai, G.Y.; Fan, Y. Effect of extracts of buckwheat seed on blood glucose in type 2 diabetes mellitus rat. Mod. Preve. Med. 2008, 35, 4677-4678. [CrossRef]

26. Wang, Y.; Qi, H.X.; Gu, B.B.; Huang, W.; Zhao, H.G. The therapeutic effects of tartarian buckwheat protein extracts on 2 type diabetic rats. Zhejiang J. Prev. Med. 2009, 21, 4-6. [CrossRef]

27. Liu, R.J.; Wang, Y.J.; Guo, H.W.; Jia, S.; Hu, Y.H. Study on the effect of buckwheat protein in lowering blood glucose of diabetic mice. J. Jilin Agric. Univ. 2009, 31, 102-104. [CrossRef]

28. Wang, K.-J.; Zhang, Y.-J.; Yang, C.-R. Antioxidant phenolic constituents from Fagopyrum dibotrys. J. Ethnopharmacol. 2005, 99, 259-264. [CrossRef]

29. Ku, C.S.; Mun, S.P. Characterization of proanthocyanidin in hot water extract isolated from Pinus radiata bark. Wood Sci. Technol. 2007, 41, 235-247. [CrossRef]

30. Fu, C.; Loo, A.E.K.; Chia, F.P.P.; Huang, D. Oligomeric Proanthocyanidins from Mangosteen Pericarps. J. Agric. Food Chem. 2007, 55, 7689-7694. [CrossRef]

31. Wei, S.-D.; Zhou, H.-C.; Lin, Y.-M. Antioxidant Activities of Fractions of Polymeric Procyanidins from Stem Bark of Acacia confusa. Int. J. Mol. Sci. 2011, 12, 1146-1160. [CrossRef] [PubMed]

32. Zhang, L.L.; Lin, Y.M. HPLC, NMR and MALDI-TOF MS Analysis of Condensed Tannins from Lithocarpus glaber Leaves with Potent Free Radical Scavenging Activity. Molecules 2008, 13, 2986-2997. [CrossRef] [PubMed]

33. Zhou, H.-C.; Lin, Y.-M.; Wei, S.-D.; Tam, N.F.-Y. Structural diversity and antioxidant activity of condensed tannins fractionated from mangosteen pericarp. Food Chem. 2011, 129, 1710-1720. [CrossRef]

34. Gu, L.; Kelm, M.A.; Hammerstone, J.F.; Beecher, G.; Holden, J.; Haytowitz, A.D.; Prior, R.L. Screening of Foods Containing Proanthocyanidins and Their Structural Characterization Using LC-MS/MS and Thiolytic Degradation. J. Agric. Food Chem. 2003, 51, 7513-7521. [CrossRef]

35. Rigaud, J.; Escribano-Bailon, M.; Prieur, C.; Souquet, J.-M.; Cheynier, V. Normal-phase high-performance liquid chromatographic separation of procyanidins from cacao beans and grape seeds. J. Chromatogr. A 1993, 654, 255-260. [CrossRef]

36. Li, H.; Xiao, F.C.; Yuan, C.L.; Wang, H. Determination of the proanthocyanidin in the ultrafine powder of grape seeds by catalytic colorimetry with ferric ions. Food Res. Dev. 2007, 28, 114-117. [CrossRef]

37. Gullickson, E.R.; Krueger, C.G.; Birmingham, A.; Maranan, M.; Reed, J.D. Development of a Cranberry Standard for Quantification of Insoluble Cranberry (Vaccinium macrocarpon Ait.) Proanthocyanidins. J. Agric. Food Chem. 2019, 68, 2900-2905. [CrossRef]

38. Czochanska, Z.; Foo, L.Y.; Newman, R.H.; Porter, L.J. Polymeric proanthocyanidins. Stereochemistry, structural units, and molecular weight. J. Chem. Soc. Perkin Trans. 1 1980, 1, 2278-2286. [CrossRef]

39. Porter, L.J.; Newman, R.H.; Foo, L.Y.; Wong, H.; Hemingway, R.W. Polymeric proanthocyanidins. 13C N.m.r. studies of procyanidins. J. Chem. Soc. Perkin Trans. 1 1982, 1, 1217-1221. [CrossRef]

40. Xie, H.Q.; Chu, S.S.; Zha, L.P.; Cheng, M.E.; Jiang, L.; Ren, D.D.; Yu, Y.; Peng, H.S.; Peng, D.Y. Determination of the species status of Fallopia multiflora, Fallopia multiflora var. angulata and Fallopia multiflora var. ciliinervis based on morphology, molecular phylogeny, and chemical analysis. J. Pharmaceut. Biomed. 2019, 166, 406-420. [CrossRef]

41. Yang, B.J.; Liu, Y.; Wang, Q.; Ma, S.C.; Wang, A.G.; Cheng, X.L.; Wei, F. Characterization and identification of the chemical constituents of Polygonum multiflorum Thunb. by high-performance liquid chromatography coupled with ultraviolet detection and linear ion trap FT-ICR hybrid mass spectrometry. J. Pharmaceut. Biomed. 2019, 172, 149-166. [CrossRef]

42. Gan, R.-Y.; Kuang, L.; Xu, X.-R.; Zhang, Y.; Xia, E.-Q.; Song, F.-L.; Li, H.-B. Screening of Natural Antioxidants from Traditional Chinese Medicinal Plants Associated with Treatment of Rheumatic Disease. Molecules 2010, 15, 5988-5997. [CrossRef]

43. Jovanović, M.; Tenji, D.; Nikolić, B.; Srdić-Rajić, T.; Svirčev, E.; Mitić-Ćulafić, D. In Vitro Study of Two Edible Polygonoideae Plants: Phenolic Profile, Cytotoxicity, and Modulation of Keap1-Nrf2 Gene Expression. Foods 2021, 10, 811. [CrossRef] 
44. Cai, Y.; Wu, L.; Lin, X.; Hu, X.; Wang, L. Phenolic profiles and screening of potential $\alpha$-glucosidase inhibitors from Polygonum aviculare L. leaves using ultra-filtration combined with HPLC-ESI-qTOF-MS/MS and molecular docking analysis. Ind. Crop. Prod. 2020, 14, 154. [CrossRef]

45. Wan, S.Q.; Zhang, J.F.; Hou, R.; Zheng, M.S.; Liu, L.Y.; Zhang, M.S.; Li, Z.Y.; Huang, X.L. A strategy for component-based Chinese medicines design approach of Polygonum orientale L. against hypoxia/reoxygenation based on uniform design-stepwise regression-simulated annealing. Biomed. Pharmacother. 2021, 135, 111177. [CrossRef]

46. Zhang, X.R.; Zhang, M.S.; Wang, Z.X.; Zhu, N.; Zhang, J.F.; Sha, Z.J.; Li, Z.Y.; Huang, X.L. A review of the traditional uses, phytochemistry, pharmacology and quality control of the ethnic medicinal plant Persicaria orientalis (L.) Spach in China. J. Ethnopharmacol. 2020, 113521. [CrossRef]

47. Kucekova, Z.; Mlcek, J.; Humpolicek, P.; Rop, O.; Valasek, P.; Saha, P. Phenolic Compounds from Allium schoenoprasum, Tragopogon pratensis and Rumex acetosa and Their Antiproliferative Effects. Molecules 2011, 16, 9207-9217. [CrossRef]

48. Ullah, H.M.A.; Kim, J.; Rehman, N.U.; Kim, H.-J.; Ahn, M.-J.; Chung, H.J. A Simple and Sensitive Liquid Chromatography with Tandem Mass Spectrometric Method for the Simultaneous Determination of Anthraquinone Glycosides and Their Aglycones in Rat Plasma: Application to a Pharmacokinetic Study of Rumex acetosa Extract. Pharmaceutics 2018, 10, 100. [CrossRef]

49. Ceccanti, C.; Landi, M.; Incrocci, L.; Pardossi, A.; Guidi, L. Suitability of Hydroponically-Grown Rumex acetosa L. as Fresh-Cut Produce. Horticulturae 2020, 6, 4. [CrossRef]

50. Ceccanti, C.; Landi, M.; Incrocci, L.; Pardossi, A.; Venturi, F.; Taglieri, I.; Ferroni, G.; Guidi, L. Comparison of Three Domestications and Wild-Harvested Plants for Nutraceutical Properties and Sensory Profiles in Five Wild Edible Herbs: Is Domestication Possible? Foods 2020, 9, 1065. [CrossRef]

51. Yamaguchi, M.; Wakasugi, J.; Sakakima, J. Competitive and product inhibition-based $\alpha$-amylase activity analysis method. Clin. Biochem. 2008, 41, 325-330. [CrossRef] [PubMed]

52. Sharma, O.P.; Bhat, T.K. DPPH antioxidant assay revisited. Food Chem. 2009, 113, 1202-1205. [CrossRef]

53. Re, R.; Pellegrini, N.; Proteggente, A.; Pannala, A.; Yang, M.; Rice-Evans, C. Antioxidant activity applying an improved ABTS radical cation decolorization assay. Free Radic. Biol. Med. 1999, 26, 1231-1237. [CrossRef]

54. Benzie, I.F.F.; Strain, J.J. The ferric reducing ability of plasma (FRAP) as a measure of "antioxidant power": The FRAP assay. Anal. Biochem. 1996, 239, 70-76. [CrossRef]

55. Apak, R.; Güçlü, K.; Özyürek, M.; Çelik, S.E. Mechanism of antioxidant capacity assays and the CUPRAC (cupric ion reducing antioxidant capacity) assay. Microchim. Acta 2007, 160, 413-419. [CrossRef] 